University of Louisville

ThinkIR: The University of Louisville's Institutional Repository

8-2008

\title{
Multimodal and print composition : an examination of instructors and students transferring rhetorical knowledge in first-year composition.
}

Sonya Compton Borton

University of Louisville

Follow this and additional works at: https://ir.library.louisville.edu/etd

\section{Recommended Citation}

Borton, Sonya Compton, "Multimodal and print composition : an examination of instructors and students transferring rhetorical knowledge in first-year composition." (2008). Electronic Theses and Dissertations. Paper 131.

https://doi.org/10.18297/etd/131

This Doctoral Dissertation is brought to you for free and open access by ThinkIR: The University of Louisville's Institutional Repository. It has been accepted for inclusion in Electronic Theses and Dissertations by an authorized administrator of ThinkIR: The University of Louisville's Institutional Repository. This title appears here courtesy of the author, who has retained all other copyrights. For more information, please contact thinkir@louisville.edu. 
MULTIMODAL AND PRINT COMPOSITION: AN EXAMINATION OF INSTRUCTORS AND STUDENTS TRANSFERRING RHETORICAL KNOWLEDGE IN FIRST-YEAR COMPOSITION

\author{
By \\ Sonya Compton Borton \\ B.A., Bellarmine University, 1992 \\ M.A., Murray State University, 1994

\begin{abstract}
A Dissertation
Submitted to the Faculty of the

Graduate School of the University of Louisville

in Partial Fulfillment of the Requirements

for the Degree of
\end{abstract} \\ Doctor of Philosophy \\ Department of English \\ University of Louisville \\ Louisville, Kentucky
}

August 2008 
Multimodal and Print Composition: An Examination of Instructors and Students

Transferring Rhetorical Knowledge in First-Year Composition

$$
\text { By }
$$

Sonya Compton Borton

B.A., Bellarmine College, 1992

M.A., Murray State University, 1994

A Dissertation Approved on

August 4, 2008

by the following Dissertation Committee:

Dissertation Director 


\section{DEDICATION}

This dissertation is dedicated to my children

Ethan Forrest Borton

and

Emma Clare Borton

who cannot remember a time when I was not in this program.

I hope my accomplishments will inspire them to always go after their dreams. 


\begin{abstract}
MULTIMODAL AND PRINT COMPOSITION: AN EXAMINATION OF INSTRUCTORS AND STUDENTS TRANSFERRING RHETORICAL KNOWLEDGE IN FIRST-YEAR COMPOSITION
\end{abstract}

Sonya C. Borton

August 4, 2008

This dissertation is a case-study of three instructors and five of their students in first-year composition who were making the transition from print to multimodal composition. This study examines the similarities and differences in the ways instructors and students talk about print and multimodal compositions and if the vocabulary they use to talk about each transfers or if they need a new vocabulary to discuss the multimodal compositions. The results of this study seem to indicate that language common to both print and multimodal composition, such as having a clear assertion, was transferrable both between the print and multimodal projects and between the instructors and their students.

This study also indicates that multimodal composition seems to be a good place to focus on composing for a broad audience. Unlike the print text where students had trouble seeing an audience other than the instructor, all of the students interviewed were very clear about the ways their assertions or their presentation choices in the multimodal compositions would affect their audience. 
Transfer of concepts was a concern with issues of presentation because the instructors and their students had no common vocabulary about the presentation and design issues which surround multimodal composition. For instructors, presentations which did not take advantage of the affordances became "flat" or digital arguments with too much text were "heavy." The students had a "more is better" approach which relied on their intuition to guide them in making presentation decisions.

The lack of a language to talk about presentation issues combined with the time the instructors perceived that students spent on the multimodal compositions led to evaluation anxiety for the instructors. All three instructors expressed anxiety about multimodal evaluation that was not present in their evaluation of the print texts. This study both suggests that it is possible to transfer from the rhetorical vocabulary compositionists use to discuss print to multimodal compositions and that we need to work harder to increase these points of transfer. 
TABLE OF CONTENTS

PAGE

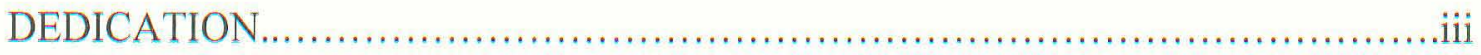

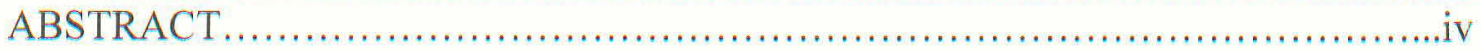

CHAPTER

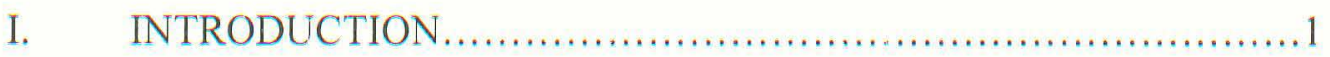

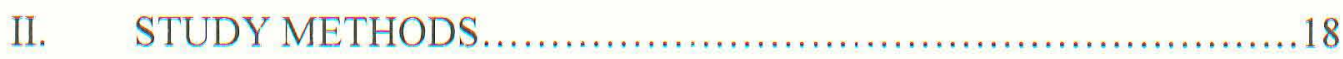

III. THE TRANSISTION FROM PRINT TO MULTIMODAL................28

IV. STUDENTS COMPOSING IN MULTIPLE MODES...................50

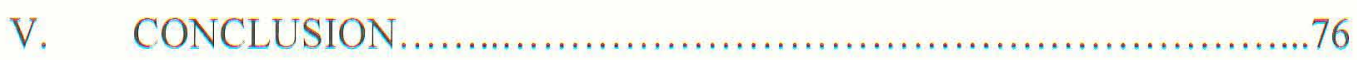

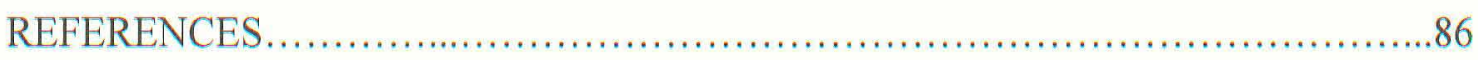

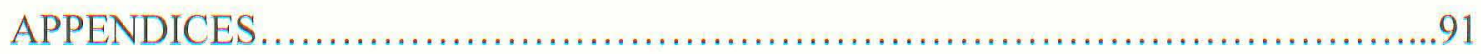

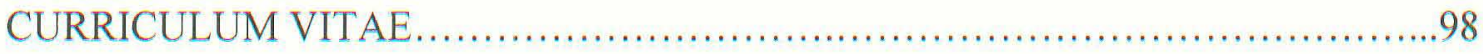




\section{CHAPTER 1 INTRODUCTION}

Almost a decade ago, Gunther Kress (1999) warned those of us in English that the field would have to change to meet the demands of a changing communication landscape. In order to meet those changing demands, there would need to be a change in how the field viewed itself and how it dealt with and taught texts. Kress believed that "our present theories of language and meaning are simply inadequate and inappropriate for the task which English will need to perform" (p. 67). That changing communication landscape had been outlined three years earlier by Kress and his colleagues of the New London Group (1996). In their description of the new landscape of communication, "mere literacy" pedagogy, or pedagogy focused on a "singular national form of language," would be insufficient to meet the needs of the rapidly changing communication media. Instead, literacy pedagogy would need to embrace multiliteracies and create a different kind of pedagogy, "one in which language and other modes of meaning are dynamic representational resources, constantly being remade by their users as they work to achieve their various cultural purposes" (p. 64) and educators would need to be prepared to provide students with the ability to engage critically with the new literacies.

Many scholars acknowledged this message as a call to action to broaden the focus of English studies to include the visual and new media texts in the curriculum. Scholars argued that composing multimodal texts offers students the chance to get in step in the classroom with their current composing practices outside the classroom (such as Web Logs, instant 
messaging, etc.) (Yancey, 2004) as well as helping the students prepare themselves technologically for future employment opportunities (Callow, 2006). Elizabeth Daley advised that "those who are truly literate in the twenty-first century will be those who learn to both read and write the multimedia language of the screen" (2003, p. 34). In recent years, the focus on the visual and its ability to de-center the written word in modern media has been a popular topic in all levels of English education (George, 2002; Hill, 2004; Hobbs, 2004; Kenner, 2004; Jewitt, 2005; Metros \& Woolsey, 2006; Selfe, 2004). Steve Westbrook (2006), in "Visual Rhetoric in a Culture of Fear: Impediments to Multimedia Production," contends that having students learn to critically read multimedia texts is very important. What is even more important, he contends, is having students author their own multimodal texts. When composing multimodal texts, students must evaluate, analyze and interpret sources; they must make decisions about presentation, design, and arrangement; they must synthesize information, data and evidence; they must analyze and understand their audience. In other words, students must use critical reading and thinking skills in conjunction with the rhetorical situation in order to create a text that is rhetorically appropriate and persuasive (Westbrook, 2006).

The language of design is a frequent theme in research on MM composition. This focus on design within multimodal composition is often credited to the New London Group (1996) who proposed that the "metalanguage of multiliteracies [be] based on the concept of "design"" (73). Bezemer and Kress explain the move from the focus on the rhetorical composition of a text to the design of the text an enhanced way of examining the text which, 
mirrors a social shift from competence in a specific practice conceived in terms of understanding and adherence to convention governing the use of a mode ... to a focus on the interest and agency of the designer in the making of signs-as-texts. Design is the practice where modes, media, frames, and sites of display on the one hand, and rhetorical purposes, the designer's interests, and the characteristics of the audience on the other are brought into coherence with each other. (p. 174)

For example, Jon Callow follows a Year 6 class for ten weeks as they create political pamphlets for the Environment Officer election at their school. Using storybooks and picture books, the students were taught visual concepts and visual grammar terms for the project which were centered on the "representational aspect"-such as the expression on a person's face if a picture were used, the use of symbols within the picture, the background, etc., the "interactive aspect"- - such as the angle of the picture and the use of color, and the "compositional aspect"--or the size and salience of the figure in the photo. Once the students were able incorporate the new visual grammar to analyze the use of these elements in the books, they moved to creating their pamphlets, always with a focus on the design features of the visual elements involved.

While this focus on design is certainly necessary, it sometimes seems very remote from the concepts most compositionists are used to teaching their students. For instance, the New London Group (1996) discussed multiliteracies in terms of Linguistic Design, Visual Design, Audio Design, Gestural Design, Spatial Design, and Multimodal Design (78). These design grammars became the basis for multimodal rubrics developed by Kress and van Leeuwen (2001) to apply to new media texts. Lev Manovich's cinematic 
approach to new media (2001) seems even further removed from composition. For Manovich, new media texts must include five principles centered on cinematic language: numerical representation, modularity, automation, variability, and transcoding. For instructors new to multimodal composition, these design terms are an entirely new language than the rhetorical language they use when teaching print text compositions.

Daniel Keller is clearly making gestures toward rhetoric with his mention of ethos, pathos, and logos in "Thinking Rhetorically" (2007). The influence of both Kress and van Leeuwen and Manovich seems to dominate Keller's analysis. This chapter from Multimodal composition: Resources for teachers, a how-to guide for instructors who want to include multimodal texts in their composition classes, offers key terms instructors should consider when teaching multimodal projects. Keller explains that the terms will help students "as they engage in rhetorical analyses of multimodal texts" (p. 53). However, the terms such as: Camera Angle, Voice Over, Soundmark, and Establishing Shot are all features of multimodal and visual design rather than terms compositionists think of when discussing rhetorical conventions. For example, Keller uses Beth Powell's audio essay, "Literacy and Public Transportation" (2007), to illustrate how this new vocabulary can be used to analyze multimodal compositions:

Beth uses a series of audio and video moves that complement each other to provide viewers with a rhetorically effective transition from the contextsetting work she did in the video's introduction to the main subject of Mary's story. During this series of moves, she simultaneously fades out a photograph of Freedom Riders looking at the charred remains of a bus to a black screen (visually signaling the end of the history segment) and fades 
out the Buffalo Springfield song to a moment of silence (providing an auditory signal that the sequence is ending). Next, Beth fades in visually on a title screen announcing the new topic ... and fades in to a new auditory soundmark ... and a segment of voice over narration provided by Beth's mother. With these carefully coordinated rhetorical transitions, Beth ends one segment of the video and begins another. (p. 55) While the design vocabulary Keller uses is emphasized in bold, the actual rhetorical effectiveness of this transition is left up to the reader to interpret. How exactly do the fade in and fade out function rhetorically? How do these transitions connect to ethos, pathos, and logos? Is it a style issue of an arrangement issue? Keller's analysis contributes to a rhetorical vocabulary for new media composition. However more needs to be done to directly connect the design vocabulary to rhetorical issues.

A focus on design is certainly useful for talking about digital arguments, audio essays, and even scrapbooks, but it also seems to suggest that multimodal composition is remote from what we currently do as compositionists. Instructors in first-year composition are prepared in their course work and teacher training to teach their students the rhetorical vocabulary of print texts, and English has long been the place where print texts are analyzed. Cynthia Selfe (2004) points to this traditional preparation when explaining how instructors new to multimodal often feel unprepared to introduce multimodal composition into their classrooms, "It is not unusual for faculty raised on alphabetic literacy and educated to teach composition before the advent of imagecapturing software, multimedia texts, and the World Wide Web to feel inadequate to the task of teaching students about new media texts and the emerging literacies surrounding 
these texts" (p. 67). Instructors new to multimodal composition often have no background and, therefore, no ethos of their own on which to base their teaching of this new media. And though the focus on design attempts to bridge the gap between instructors' rhetorical knowledge and the elements of new media texts, as illustrated in Keller's example above, the new vocabulary implemented for discussions of design issues actually works to reinforce the novelty of multimodality.

While the results of my interviews with instructors and students seem to indicate that both groups need an effective way to discuss issues of design and presentation, a grammar based solely on design becomes problematic when dealing with new media's place in composition studies. If grammars of design are the focus of multimodal analysis, how can composition truly claim that new media has its home there? If instructors are expected to teach and students are expected to learn a completely new grammar based on design concepts, how can we still call it composition? What has happened to the focus on rhetoric we see when composition instructors teach print texts? While these questions are very rarely found in the published literature surrounding multimodal composition, for those of us who present at conferences in the field about using multimodality in our firstyear composition classrooms, these questions are standard challenges to our presentations. Despite its growing popularity in first-year composition courses, many instructors continue to be resistant to teaching multimodal composition because they cannot see its connection to teaching print text compositions or its value to students in these introductory courses. Rather than learning this new design vocabulary and how to incorporate it into the first-year composition classroom, most compositionists still favor the written text in the first-year curriculum and choose not to broaden their focus to 
include other types of composing (Takayoski \& Selfe, 2007). Ultimately, the current method of having a rhetorical grammar to discuss print text issues and a design grammar to discuss multimodal text issues seems like too much of a disconnect for these composition instructors.

Consequently, two discourses surrounding multimodal composition, the discourse of newness and the discourse of continuity, are currently in play in the discipline. The discourse of newness focuses on the newness of multimodal composition and its need for a new grammar or metalanguage to talk about it. This focus on newness can be seen in Daniel Anderson's (2008) recent Computers and Composition article about the benefits of including multimedia assignments in the writing classroom. Anderson explains that multimodality offers new ways to solve new problems because it allows for innovation in the classroom. And while innovation is certainly welcome in any classroom, the instructors expect there to be a connection between the pedagogical goal and the innovation. Kathleen Blake Yancey (2004) similarly suggests that the introduction of new media into the composing process necessitates the need for composition to move to a "new model of composing," which may seem to be the same call Kress had made five years earlier.

In contrast to the focus on innovation and newness, the discourse of continuity argues that what is lacking in the metalanguage the New London Group and others have proposed is a bridge - a way to move from the written to the multimodal and vice versa. Third on Yancey's list of considerations in this new model of composition is to "think explicitly about what [different communication media] might 'transfer' from one medium to the next: what moves forward, what gets left out, what gets added — and what [the 
composition students] have learned about composing in this transfer process" (311). The model calls for a close examination of what our knowledge of print texts has to offer our focus on new media and how we can use that prior knowledge to benefit our students and the field.

The need for continuity to bridge the gap from print to multimodal is reinforced by Anne Wysocki who explicitly argues that composition should draw from an established print text metalanguage when teaching new media because compositionists know print texts. While other disciplines (and sometimes even our own) question why multimodal texts should be taught in English, compositionists who believe multimodal composing should be based in English claim it is because of our knowledge of rhetoric and how to read and analyze texts rhetorically. Wysocki (2004) argues that "new media needs to be opened to writing. I want to argue that writing about new media needs to be informed by what writing teachers know, precisely because writing teachers focus specifically on texts and how situated people (learn how to) use them to make things happen" (p. 5). However, when we use terminology based on only design rather than also including the traditional rhetorical vocabulary that is expected of English, it becomes more difficult to defend English as the place for multimodal composition. Also, if we simply create new vocabularies without drawing from the old, then it is impossible to see what skills transfer from print composition to multimodal composition. While it is not useful to merely transfer the vocabulary compositionists use to discuss written texts directly to the multimodal, what would be useful is a metalanguage that serves as a bridge moving us from print texts to multimodal texts. 
Cheryl Ball (2006) shows the overlap and the continuity between print and multimodal composing. Ball agrees with previous scholars that multimodal composition is important to the field of writing studies, but she makes the critique that too much focus has been placed upon the design aspect of multimodal texts: "What is needed . . . is a middle ground: a way for writing teachers to interpret all of the modes of communication (as well as the designerly processes) in a new media text" (394). Like Yancey, Ball wants composition to draw on its strengths, the rhetorical analysis we use to focus on print texts because in doing so, composition will have a solid foundation on which to base its claims for teaching multimodal composition. To do this, she suggests we combine the design grammars offered by the New London Group, Kress and van Leeuwen, and Manovich with a rhetorical process of reading the multimodal texts. Ball takes these two analyses of a text, the "designerly" and the "readerly", and combines them in an attempt to create a more thorough analysis than just a focus on design.

To illustrate this, Ball offers a table with three columns, "Mode," "Element," and "Possible Readerly Meaning" to analyze the multimodal text "Chopping Red Peppers," a FLASH-based poetic text by Ankerson and Sapnar (2000) "that demonstrates the tense relationship between the speaker, characterized as a daughter, and her father" (p. 397). The modes are taken from the New London Group's design modes of linguistic, visual, audio, spatial, and gestural design. Under the mode of "Visual," Ball offers the element "the red pepper that contains the silhouetted faces of the speaker as a young girl and the father as an old man." The "possible readerly meaning" of this element is, "The overlapping silhouettes visually reflect the power struggle of the father and daughter and the subsequent tension" (p. 408). With this analysis, Ball goes a step beyond what Keller 
has done in "Thinking Rhetorically," but the focus still seems to be on the design - the way the "silhouettes visually reflect the power struggle." Similarly, when Ball talks about the spatial design the element is "the churchgoers' (i.e. men in hats) change in size and rotation" and the possible readerly meaning is "the motion and space they display on screen shows uneasiness" (408). Ball aptly observes the need to connect the design vocabulary used to examine a multimodal text with the analysis offered by a rhetorical reading. From this, scholars need to build a specific rhetorical vocabulary necessary to connect the context of multimodality to print. Ball's readerly analysis may be a good method for a sophisticated reader to approach the multimodal text, but it is unclear if this method would be transferrable to students new to multimodal texts. How transferable is this method from one rhetorical situation to the next?

This project seeks to partly take up Ball's call for more understanding between rhetoric and design. To do this, I look at how instructors and students new to multimodal composition discuss the transition from print to multimodal composition. Novice instructors will help us identify the gaps between print and multimodal composing while also allowing us to see what elements intuitively transfer across media. The elements that do intuitively transfer can then be made more explicit so that the instructors can help their students transfer that knowledge as well.

\section{The need to transfer rhetorical knowledge between print and multimodal composition}

Perhaps the strongest reason for seeking to better understand how instructors and students move between the rhetorical vocabulary of print texts and the design vocabulary of multimodal texts is so we can help students transfer lessons learned by composing multimodally back to the print compositions they will write in other college classes 
which are still necessary for professional success. Fostering an ability to transfer writing across rhetorical domains has long been one of the major goals and challenges of composition pedagogy. Anne Beaufort (1998) describes composition's goal as,

We should be helping our students develop that metacognitive awareness that will enable them to generalize across writing situations and solve any number of different writing problems. At the same time we must call our students' attention to the very context-specific nature of composing . .. so that they ... can see the interrelationship of context and general writing principles. (196)

It is the process of being able to "generalize across writing [or composing] situations" and seeing "the interrelationship of context and general writing principles" that seems to have been left out of multimodal composition instruction. If we cannot help students explicitly understand the connections between print and multimodal texts, it is unlikely they will be able to intuit these connections themselves. How can instructors make connections for themselves and for students that will help the students understand that multimodal composing is another way of composing the same genres they compose in print rather than being something completely new and unconnected from their previous writing experiences? How can we help them to bridge the gap between print and multimodal composition?

Research on knowledge transfer shows that the lessons students learn composing multimodally will not necessarily transfer to their print text compositions. This again raises the question of whether we should teach multimodal composition in first-year composition since the vast majority of college and professional writing is still print- 
based. Knowledge transfer is the key to the rational for teaching multimodal composition. Not only is knowledge transfer a good goal in and of itself, but focusing on knowledge transfer also makes strategic sense for users of multimodality.

Transfer is a challenging goal at best but there are strategies that can aid instructors in this quest. Knowledge transfer, or "the ability to apply knowledge gained in one situation to . . another similar situation" (Lauder, Reynolds, \& Angus, 1999, p. 480), appears to be contextual. In published research on transferring knowledge of writing skills, knowledge transfer was most successful when writers were able to make connections within the context of the writing situations-when the writers had a clear sense of the expectations of their discourse community and thus knew the appropriate conventions for the audience and context-and least successful when the writers saw no connections in the context, such as moving from a technical writing assignment in a writing course to a writing task in the workplace where they felt the discourse community was new and different from their academic discourse community (Herrington, 1985; McCarthy, 1987; Doheny-Farina, 1989; Ackerman, 1991; Haas, 1994; Beaufort, 1998; Kryder, 1999; Mila \& Sanmarti, 1999; Ford, 2(104). Thus a 1987 study by Lucille Parkinson McCarthy revealed that even though the student, Dave, had three very similar writing assignments for his Poetry, First-year Composition, and Biology classes, because the contexts for writing and the ways of discussing the writing were so different from class to class, "Dave interpreted [the writing assignments] as being totally different from each other and totally different from anything he had ever done before" (p.243). Similarly, Herrington (1985) discovered that even within the context of the same discipline (chemical engineering), "different courses may represent distinct forums where 
different issues are addressed, different lines of reasoning used, different writer and audience roles assumed, and different social purposes served by writing" (p. 354). In order for connections to be made and carried across the classes, a community or similar context must exist.

Multimodal and print compositions differ contextually as is illustrated by all of the scholars who talk about the newness of multimodal composition to the field and its difference from print (New London Group, 1996; Kress, 1999; Kress and van Leeuwen, 2001; Daley, 2003; Yancey, 2004). Moreover, intuitively for students, multimodality is associated with everyday literacies while the print text essay is most often associated with the classroom and academic composition. Examples of these "everyday literacies" include music literacy exhibited in music videos found on YouTube or MySpace, sports literacy which can focus on a specific sport, fantasy sports, or even the way a specific team or player plays that sport, visual literacy found in commercials, and literacies of the home such as needle work, wood working, or cooking. Much of the research on multimodal composition similarly focuses on how multimodality extends everyday literacies. For instance, my previous work with multimodal texts and assignments (Borton, 2005) similarly focused on the transformative properties of multimodal composition. I noted that students' enthusiastic engagement with the compositions due to a focus on their everyday literacies can transform the students from apathetic composers of print text to engaged composers (and even revisers) of multimodal texts. Likewise, Glynda Hull, both by herself and with coauthors, has focused her multimodal scholarship on the DUSTY program in Oakland, CA which concentrates on digital storytelling and the agentive power that composing in a multimodal format allows underrepresented 
groups (Hull, 2003; Hull \& Nelson, 2005; Hull \& Katz, 2006). Students have the chance to tell the stories about their lives which are important to them.

Scholars have focused on multimodal composition's ability to open the first-year composition classroom up to different cultures and communities which have not thrived typically under more traditional writing pedagogy, Marilyn Cooper (2005), Anne Wysocki (2004), and others (New London Group, 1996; Hawisher \& Selfe, 1999; Kress, 1999; Stein, 2004; Hamston, 2006; Vincent, 2006; Takayoski \& Selfe, 2007) have discussed the ability of multimodal composition to engage students and allow them to express more of their own identities due to the fact that they can incorporate their everyday literacies. Thus if we want to find a way for students to transfer the concepts learned in composing multimodally to their print compositions, we must find a way to bridge the contexts between the popular and the academic as well as the old and the new.

Explicit training on adapting to contexts is key to developing this bridge which will allow for knowledge transfer. Dave's inability to see the contextual connections in his three writing assignments lead McCarthy to conclude that instructors need to offer "explicit training in the ways in which one figures out and then adapts to the writing demands in academic contexts" (p. 262). This conclusion is reinforced by a 2004 study by Julia Dyke Ford. In "Knowledge transfer across disciplines: Tracking rhetorical strategies from a technical communication classroom to an engineering classroom," results of the study of knowledge transfer in twelve senior-level college students indicated that, "for transfer to occur, teachers need to facilitate students' development of an awareness of their own writing processes" (p. 311). One of the ways Ford suggested instructors do that is to commit to "learning and using a common vocabulary in the 
classroom" (p. 311). If these common terms are employed by instructors in the classroom, the students will be better able to learn the concepts associated with the terms in their classroom projects and then be able to transfer that knowledge to a different context when it arises. This reinforces the need for more research on what transfers (and what does not) between print and multimodal composition.

Thus, in order to determine how to bridge the gap between print texts and multimodal texts and what will transfer from one to the other thus keeping multimodal composition legitimately in the field of composition, we need to ask the following questions: What happens as instructors and students make the transition from print composition to multimodal composition? Which concepts seem to "naturally" transfer and what concepts make print and multimodality seem like foreign territories? What is truly new and different about multimodal composition and what are the instructors able to transfer from their experience teaching print texts to multimodal composition? Also, we need to know what students are able to take from these varying types of composition. What concepts transfer from print to multimodal or vice versa for the students? Do they transfer the terms their teachers use into their own composition vocabulary? In what specific areas are they more successful or less successful at transferring the information? This information is necessary both to improve transfer between print and multimodal compositions and to justify teaching multimodal composition in English. Answers to these questions would also help compositionists determine the best way to integrate multimodal composition into the existing first-year composition curriculum. 


\section{Introduction to the Project}

This dissertation examines the similarities and differences in the ways instructors and students talk about print and multimodal compositions and if the vocabulary they use to talk about each type of composition transfers or if they need a new vocabulary to discuss the multimodal compositions. In what ways do instructors intuitively transfer concepts from teaching print texts to teaching multimodal composition? These are the concepts we need to make explicit to instructors. In what areas are there gaps? How can we make these gaps explicit in order to begin to find ways to connect them?

\section{Chapter Overviews}

Chapter 2 explains the methodology used to conduct the research for the project.

Chapter 3 is a case study of three first-year composition instructors teaching multimodal composition for the first time. My findings suggest that, not surprisingly, instructors new to multimodal composition draw heavily on their experience teaching print texts to teach new media. They use print text language such as "assertion" and "evidence" when articulating the necessity of having a clear thesis with supporting evidence in the multimodal composition. Yet when the instructors move to issues unique to multimodal composition, such as presentation, they resort to a vocabulary of the physical world. The instructors in this study exhibit anxiety about evaluating the multimodal projects due to the increased amount of time and emotion they perceive students have put in to these assignments.

Chapter 4 introduces interviews with five students from the courses taught by the three novice instructors. Students were asked to discuss the print and multimodal 
projects they created as well as what rhetorical choices they made during those assignments. The findings suggest that, like their instructors, the students are able to transfer print text concepts to their multimodal projects but are in need of a rhetorical vocabulary to discuss their presentation choices. However, rather than a vocabulary of the physical world, the students had no specific vocabulary on which to draw their descriptions of presentation issues. The students instead relied on their intuition for presentation decisions and exhibited a "more is better" mentality when it came to issues of layering.

Chapter 5 concludes the dissertation and discusses implications of the study as well as directions for further research. 


\section{CHAPTER 2 STUDY METHODS}

This project examines how composition instructors new to teaching multimodal composition and their students make the transition from print texts to multimodal texts. What are the similarities and differences in the ways the instructors and students talk about the print and multimodal compositions? Do they talk about the elements of each text the same way or does multimodal composition require a different vocabulary than the rhetorical vocabulary they use to discuss the print texts? Do the instructors and students have the same challenges in talking about the two different composition media or are their challenges different?

The subjects for this study included three graduate teaching assistants from the University of Louisville and five of their students. The principle of selection for the instructors was that they had previous experience teaching first-year composition, but they had never taught multimodal composition. The instructors had various levels of teaching experience but each was teaching the multimodal composition for the first time in the Spring 2007 semester. It was important to interview instructors new to multimodal composition because these novice instructors had not yet had time to compensate for the differences in teaching students to compose in the various types of media. Thus they would make the gaps between teaching print texts and multimodal texts more clear and would also help us to see what elements intuitively transfer from one medium to the 
other. The principle of selection for the students was that they had to be students in these three instructors courses in order for me to analyze their interviews compared to their instructors' interviews and determine when issues transferred or when they did not transfer from instructor to student and vice versa. The instructors volunteered for the study because they were each interested in teaching multimodal composition and thought this would be a good opportunity to incorporate it into their classrooms. After interviewing each of the instructors twice and each student once, I analyzed the conversations to determine what concerns were raised and to isolate common themes.

This project has been approved by the University of Louisville's IRB \#158.07.

\section{Participants-Instructors}

The instructors were all female $\mathrm{PhD}$. candidates at the University of Louisville who each taught multimodal composition for the first time in the Spring 2007 semester. Allison was 27 years old and had been teaching for approximately five years, Michelle was 38 years old with approximately seven years of teaching experience, and Rachel was 40 years old with approximately five years of teaching experience. The instructors volunteered for the study because none of them had previously taught multimodal composition, but they had each been interested in teaching multimodal assignments. They saw this as a good opportunity to incorporate multimodal composition into their classes. I asked two of the instructors to teach the multimodal project first followed by the print text and the other instructor to teach the print text first followed by the multimodal. However, it was their decision when to teach these two assignments during the course of the semester. 
Michelle taught high school for three years and spent time as a writing specialist for a school district in Alabama. She had been a graduate teaching assistant since 2000, first as an MA student for a university in Alabama, and then as a $\mathrm{PhD}$ student for the University of Louisville. She taught basic writing, composition for ESL students, and the first-year composition sequence. Michelle had no previous experience composing multimodally or teaching multimodal composition, but she was interested in incorporating it into her first-year composition course. To prepare herself and her students for the Spring 2007 course, she developed a syllabus with readings in new literacy studies by scholars such as Jody Shipka, Barton and Hamilton, and Deborah Brandt.

Allison had been a graduate teaching assistant since 2002. She taught as an MA student at a university in Tennessee before coming to the University of Louisville. Her teaching experience consisted of the first- year composition sequence, business writing, and a literature course titled "Writing about Literature." Like Michelle, Allison had no previous experience composing multimodally or teaching multimodal composition, but she was interested in incorporating it into her first-year composition course. She and Michelle collaborated on the syllabus of their first-year composition courses. Thus their classes mirrored each other as far as the reading and composing assignments.

Rachel had also been teaching as a graduate assistant since 2002, first as an MA student at a university in south-central Kentucky, and then at the University of Louisville. She taught the first-year composition sequence, business writing, and scientific and technical writing. In addition, she worked with the National Writing Project on both campuses. Rachel had no previous experience teaching multimodal composition, but she 
did create a digital argument encouraging young women to be vaccinated for HPV to show to her students as an example of the multimodal assignment they were asked to complete.

\section{Participants-Students}

The five students interviewed were in three different first-year composition classes. The students volunteered to be interviewed about multimodal composing and thus were a self selected group. All students who volunteered were selected. The students were more likely to be the stronger students in their classes willing to give up their time to talk to a researcher about their composition courses. Three of the five students were in the University of Louisville's Honors Program. The students interviewed were also more likely to have enjoyed the multimodal projects because they volunteered their time to talk about them. Will and Beth were students in Michelle's English 105 course. This is the honors composition course at the University of Louisville and involves only one semester to fulfill the first-year composition requirement. Will was majoring in biology and Beth was a pre-med major with plans to be a pediatrician. Sarah was also an honors student in Allison's English 105 course and had not declared a major. A second student in Allison's class volunteered but was ultimately unable to meet with me. Pam and Emily were students in Rachel's English 102 course. This is the second semester of the two semester first-year composition sequence which typically focuses on composition and research. Pam was an elementary education major, and Emily was an English major with plans to go on to law school. 


\section{Courses \& Assignments}

In the Spring 2007 semester, Rachel taught English 102, the second course in the first-year composition sequence, while Michelle and Allison both taught English 105. English 105 is the honors version of first-year composition and only requires students to take one course rather than two.

Michelle and Allison were collaborating on their courses that semester, so they taught the same assignments at the same time all semester. The first assignment was a multimodal assignment which asked the students to choose a person and profile his or her literacy practices (see Appendix A). For the purposes of this assignment, a text was determined to be multimodal if it used a combination of two or more media, such as text with pictures or video with narration. The literacy narrative is a popular assignment at the University of Louisville for first year composition. It is often assigned in the place of the personal narrative as a way for students to begin thinking about their own writing. This assignment was a variation of the typical literacy narrative which asked the students to argue for an expanded notion of literacy. Allison and Michelle's students were free to choose their mediums for the multimodal project, creating projects such as PowerPoint presentations, travelogues, scrapbooks, audio/video presentations, and comic books. The classes looked at some multimodal projects to get an idea of the types of things they could do for their own projects, but because this was the first assignment of the semester, there was not a lot of in-depth analysis of the projects. The second assignment asked students to take the information gathered in project 1 and translate it into a print text. In addition, the second assignment asked students to include some of the required readings from class as evidence to backup the assertion they made about literacy. 
By contrast, Rachel reversed the order of the assignments requiring the print text in the first assignment and the multimodal text for the second. Rachel's first assignment of the semester was a print assignment called a "Discussion of Your Writing History." Rachel used the assignment to learn more about her students' writing and research experience, but she also incorporated two types of argument into the assignment. She asked the students to make an evaluative argument by evaluating themselves as writers and a cause and effect argument by using one or more experiences in their "literacy history" to explain how the students viewed themselves as writers now.

Rachel's second assignment was the multimodal composition in the form of a digital argument (see Appendix B). She required the students to use Movie Maker for this project and spent class time teaching them how to use the software. Rachel also created her own sample digital argument which she showed to the class to give them an idea of what their projects should look like and the different elements they should incorporate. The students were required to develop a clear proposal argument on any topic and use outside evidence to support their "call to action." Examples included an argument for requiring physical education classes throughout high school and for buying hybrid vehicles.

\section{Interview Procedures}

I conducted at least two interviews with each instructor immediately after she assessed the multimodal and print assignments in order to collect her first impressions of the projects and why she had evaluated the project the way she had. These interviews sometimes prompted another brief recall interview or email to clarify information. The interviews were audio-taped and the recordings were transcribed. In each case, the 
instructors brought student texts into the interviews that they felt fell into the categories of acceptable, unacceptable, and excellent. We examined each text, and they explained their reasons behind their evaluations. The interview questions, which asked them to describe the assignment, the challenges and benefits of the assignment, and typical excellent, acceptable, and unacceptable projects, etc., are included in Appendix B.

In order to understand the approach the students took in the creation of their multimodal compositions compared to how they approached their print compositions as well as to decrease the burden on the students of having to meet multiple times, I chose to interview them only once after they had completed both assignments and had received their grades for the projects. The student interviews were also audio-taped and the recordings were transcribed. The students were questioned about both the multimodal and the print text assignments during this interview. The student interview questions included asking them how much time they spent of each assignment, how they would describe the composing process for each assignment, and which type of composition they preferred and why. The students were also asked which element they believed was the most important criteria on which they should be evaluated for the multimodal composition.

\section{Analysis}

Based on the research of Flower and Hayes (1981), I divided the interview responses into "episodes" or "points at which there is a shift in the writer's focus of attention or goal." The episodes were then each coded three times. The first time they were coded for whether the episode is about print or multimodal composition. This was necessary because instructors occasionally mentioned the print text assignments in the 
multimodal interviews and vice versa and because the students discussed both methods of composing in the same interview. The episodes were coded a second time for eight themes which I determined were discussed most often in the instructor interviews. These are the first eight themes in Table 1. After coding the instructor and student interviews for the original eight themes, I determined "audience" should be added to the list of themes because the discussion of audience was so pervasive in the student interviews. Both the instructor and student interviews were then coded for the third time for occasions of audience. Episodes could have multiple codes, though no episode contained more than five. Most episodes had approximately two themes each.

In my final analysis, I determined that audience should be come a subset of assertion because it was almost always discussed by the students in terms of the assertion they were making. A more complete discussion of this decision will follow in Chapter 4 .

Table 1: Themes used for coding instructor and student interviews

\begin{tabular}{|c|c|c|}
\hline Name & Definition & Examples \\
\hline Assertion & $\begin{array}{l}\text { Refers to the argument the student is trying } \\
\text { to make in the composition and/ or the } \\
\text { focus of the composition. Is there a clear, } \\
\text { well-defined thesis/assertion? Are there } \\
\text { clear attempts to convince an audience? }\end{array}$ & $\begin{array}{l}\text { "One thing I've tried to do with my } \\
\text { [evaluative] comments is compare } \\
\text { [the assertion in the multimodal } \\
\text { text] to what they know about } \\
\text { writing traditional papers, and so } \\
\text { for the person who didn't have an } \\
\text { interpretation, I said this would be } \\
\text { like you having a paper where you } \\
\text { gave me a bunch of details but you } \\
\text { had no thesis." }\end{array}$ \\
\hline Process & $\begin{array}{l}\text { Refers to the comments about the } \\
\text { composing process, such as brainstorming, } \\
\text { organizing, outlining, storyboarding, } \\
\text { drafting, conferencing, revision, peer } \\
\text { review, time spent on the project, etc. }\end{array}$ & $\begin{array}{l}\text { "Sitting down and writing project } \\
2 \text {, even though it was a traditional } \\
\text { print essay, was still more difficult } \\
\text { somehow. I couldn't rely on } \\
\text { pictures to make some point; I had } \\
\text { to explain it in depth. In that } \\
\text { process, I had to think more about } \\
\text { what I was writing." }\end{array}$ \\
\hline Evidence & $\begin{array}{l}\text { Refers to students drawing on outside } \\
\text { sources such as interviews, personal } \\
\text { anecdotes, articles read during the semester, } \\
\text { or library or internet research to use as } \\
\text { evidence to back up or support the assertion }\end{array}$ & $\begin{array}{l}\text { "They did a good job of } \\
\text { incorporating graphs and statistics } \\
\text { and not just highly emotive } \\
\text { pictures." }\end{array}$ \\
\hline
\end{tabular}




\begin{tabular}{|c|c|c|}
\hline & made in their composition. & \\
\hline Name & Definition & Examples \\
\hline $\begin{array}{l}\text { Technology as } \\
\text { obstacle }\end{array}$ & $\begin{array}{l}\text { Refers to technical problems that occurred } \\
\text { during the composing process. May include } \\
\text { references to a lack of experience with the } \\
\text { technology or the newness of the medium. }\end{array}$ & $\begin{array}{l}\text { "I tried to incorporate interview } \\
\text { segments within PowerPoint and } \\
\text { that was kind of difficult because } \\
\text { PowerPoint is not really meant for } \\
\text { that." }\end{array}$ \\
\hline Presentation & $\begin{array}{l}\text { Refers to the way the student used the } \\
\text { affordances of the mode. Did the student } \\
\text { use text and sound and pictures in Movie } \\
\text { Maker effectively to relay his or her ideas } \\
\text { about the subject to the instructor? If this } \\
\text { was a "paper" project, did the student take } \\
\text { advantage of the white space, headings, } \\
\text { page numbering, etc. to make the paper } \\
\text { easier for the instructor to maneuver } \\
\text { through? Did the paper allow the student to } \\
\text { go into more depth or have a richer } \\
\text { description of an experience? May also } \\
\text { include references to page length or } \\
\text { transitions. }\end{array}$ & $\begin{array}{l}\text { "There were two pages. One page } \\
\text { would have a quote I felt explained } \\
\text { the part of my subject's life that I } \\
\text { was trying to express to my } \\
\text { readers, and the second page had } \\
\text { the images that would express the } \\
\text { argument for the page." }\end{array}$ \\
\hline Evaluation & $\begin{array}{l}\text { Refers to instructors' discussions of how the } \\
\text { actual evaluation occurred. }\end{array}$ & $\begin{array}{l}\text { "One of the students earned an } \\
\text { excellent on the second project as } \\
\text { well. Her thesis statement was } \\
\text { very strong. It was just very well } \\
\text { argued with really great detail." }\end{array}$ \\
\hline $\begin{array}{l}\text { Everyday } \\
\text { literacies }\end{array}$ & $\begin{array}{l}\text { Refers to specific literacies other than } \\
\text { academic literacy expressed through } \\
\text { reading and writing. For example, everyday } \\
\text { literacies might include explicit references } \\
\text { to music literacy, computer literacy, or } \\
\text { sports literacy. }\end{array}$ & $\begin{array}{l}\text { "She is profiling her brother's } \\
\text { musical literacy, and she makes } \\
\text { lots of connections between that } \\
\text { literacy and traditional literacy." }\end{array}$ \\
\hline $\begin{array}{l}\text { Student } \\
\text { enthusiasm }\end{array}$ & $\begin{array}{l}\text { Refers to enthusiasm or enjoyment } \\
\text { expressed by the student about the } \\
\text { composition assignment or getting to work } \\
\text { on the composition. May also include } \\
\text { comments about resistance or lack of } \\
\text { enthusiasm about the project. }\end{array}$ & $\begin{array}{l}\text { "At first I was like, I don't like this } \\
\text { multimodal thing. I have never } \\
\text { done anything like it." }\end{array}$ \\
\hline Audience & $\begin{array}{l}\text { Refers to discussions of the way students' } \\
\text { texts affect the readers. }\end{array}$ & $\begin{array}{l}\text { "It is important for the student to } \\
\text { consider the audience he is trying } \\
\text { to reach. If it's an audience that is } \\
\text { ignorant of the concepts, they } \\
\text { would need to have some kind of } \\
\text { background on that." }\end{array}$ \\
\hline
\end{tabular}


A second reader coded the instructor interviews in order to get inter-rater reliability. Approximately $10 \%$ of the episodes were randomly chosen by putting the episodes from each interview into a hat and drawing $10 \%$ of the total episodes for that interview for a total of 20 episodes out of 192 that were recoded. The reader was first given ten sample episodes and the theme rubric. After we read and discussed the rubric, he coded the sample episodes and we discussed both the similarities and differences in our coding. Then the reader coded the twenty randomly selected episodes. First, I determined whether the researcher's primary code for each episode was matched by any of the second rater's codes. Inter-rater agreement using this measure was $\mathrm{k}=.82$ using Cohen's simple kappa. When inter-rater reliability was calculated to see if the researcher's second code matched any of the rater's codes, inter-rater agreement was $\mathrm{k}=.87$ using Cohen's simple kappa. These levels represent agreement substantially above chance.

The next two chapters discuss the results of the instructor and student interviews. Chapter 3 looks at the instructor interviews to determine how instructors new to multimodal composition dealt with the assessment of this new form of composition. Chapter 4 is a discussion of how students compared and contrasted multimodal composition with traditional print composition and how their responses compared to the responses of their instructors. 


\section{CHAPTER 3 \\ THE TRANSITION FROM PRINT TO MULTIMODAL COMPOSITION: THREE INSTRUCTORS' PERSPECTIVES}

This chapter addresses how instructors new to multimodal composition make the transition from teaching print texts to teaching multimodal texts. In Literacy in the New Media Age, Gunther Kress advises us that even though language as speech will remain a major mode of communication in the future, "language as writing will increasingly be displaced by image in many domains of public communication" (2003, p. 1). With this shift in modes of public communication from language-centered to image-centered comes a need to examine the way compositionists consider literacy pedagogy and the way they instruct their students to read and compose rhetorically in the new media available to them. What are the similarities and differences in the ways instructors talk about print and multimodal compositions? How do instructors transfer the vocabulary they use in teaching print texts to teaching multimodal compositions? Do they need a new vocabulary to discuss the multimodal compositions or does the print text vocabulary suffice? Are they able to communicate their expectations for these projects to the students or are there communication gaps due to teaching a new medium?

The goals of this chapter are to determine how instructors new to multimodal composition instruction approach the teaching of new media texts compared to traditional print texts. When asking these questions about the similarities and differences in the way the texts are taught, it is important to consider instructors who are experienced 
compositionists but who are new to multimodal composition. These novices to new media will more clearly illustrate the gaps in teaching the differing modes. Unlike experienced instructors of multimodal composition. they will not yet have compensated for what may be lacking in their print composition vocabulary. An examination of novice instructors of multimodal composition can also help to determine what academic literacy concepts are not addressed in multimodal composition. Do instructors focus too much on the technology at the expense of more traditional concerns? Do they put as much emphasis on evidence and appropriate citations? Ultimately. this chapter will help compositionists to understand what kind of training and support instructors new to multimodal composition will need. As more universities begin offering multimodal composition in their first year composition classrooms. there will be more of a need for this type of training among instructors.

In this chapter. I analyze interviews with three instructors at the University of Louisville who were new to teaching multimodal composition about their experiences teaching and assessing multimodal compositions compared to similar print text assignments. By asking instructors about their evaluation criteria we can see what concepts they are comfortable with and where there are gaps in vocabulary or understanding. I will also examine which of those criteria were used most often in their discussions of each medium. Were there criteria that were discussed more often in the multimodal than the print? If so. what does that mean about composing in the two mediums? Were the instructors able to discuss print and multimodal composition in the same way? 
The instructors were interviewed twice - once immediately after assessing the multimodal projects and once immediately after assessing the print projects. They were asked the same questions about each project (see Appendix C). The interviews were then analyzed and coded for common themes. I compared instructors ${ }^{*}$ discussions of print texts to their discussions of multimodal compositions in order to see the differences in their treatment of the texts. My research questions for this chapter include the following: 1) What are the similarities and differences in the ways instructors talk about print and multimodal texts: 2) What themes emerge when instructors discuss their evaluation of multimodal compositions?

Results of this chapter indicate that while instructors are able to transfer print text vocabulary to multimodal composition, they need a rhetorical vocabulary to discuss issues of presentation in multimodal composition. Instructors also experience evaluation anxiety due to the perceived amount of time and personal investment students put into their multimodal compositions.

\section{RESULTS}

\section{Overview of Themes}

Table 1 overviews the types of themes instructors raised in the interviews and illustrates that there are more similarities than differences when discussing evaluation criteria for the two types of assignments. The results are complicated by the fact that the instructors expressed higher expectations for the second assignment which was a print assignment for two of the three instructors. However. even given this concern. Table 1 shows that instructors do use similar academic vocabulary and share similar academic 
concerns when discussing print and multimodal assignments. A more detailed discussion of each element occurs later in the chapter.

Table 1: Percentage of the time each theme came up in instructor interviews

\begin{tabular}{lrr}
\hline \multicolumn{1}{c}{ Themes } & $\begin{array}{c}\text { Multimodal Text } \\
\text { Occurrences }\end{array}$ & $\begin{array}{c}\text { Print Text } \\
\text { Occurrences }\end{array}$ \\
\hline Assertion (Audience) & $75 \%$ & $58 \%$ \\
Presentation & $51 \%$ & $21 \%$ \\
Evidence & $37 \%$ & $45 \%$ \\
Evaluation & $32 \%$ & $20 \%$ \\
Technology as Obstacle & $15 \%$ & $0 \%$ \\
Process & $11 \%$ & $10 \%$ \\
Everyday Literacies & $10 \%$ & $3 \%$ \\
Student Enthusiasm & $8 \%$ & $0 \%$ \\
Total Episodes & 100 & 92 \\
\hline
\end{tabular}

*because each episode could be coded multiple times. percentages add up to over 100\%

A clear assertion was the element most often discussed during the instructor interviews, regardless of the composition's medium. When evaluating the compositions. all three instructors agreed that a clear assertion was the first element they looked for in both assignments. The instructors did not seem to find the students had more trouble articulating the assertion due to the medium, and they often made the statement that students who had trouble developing a clear assertion in one medium had trouble in the other medium as well.

Evidence was the second most often discussed element of the paper texts and third most often discussed of the multimodal texts. Evidence was defined more loosely for the first project than the second, and all three instructors expected students to have some type of evidence to back up their assertions in both the paper and multimodal assignments. The type of evidence that counted in each project depended more on when the project came in the semester than the medium used for the project. For the first 
project, evidence included any source such as personal anecdotes. interviews with the person whose literacy practices the student wanted to profile. articles read during the semester, or textual research that could back up or support the assertion made in their composition. For the second project. all three instructors expected textual evidence from outside sources and proper citations in addition to the other types of evidence. Therefore, even though Table 1 shows more emphasis on evidence in the print project. this is probably due to assignment order. That is. overall. traditional academic concerns were referenced roughly equivalent in both media.

Presentation was the second most often discussed element of the multimodal composition while it ranked third in print text occurrences. For the purposes of this discussion. presentation was defined as the way students used the affordances of the chosen medium. In the multimodal projects. presentation could mean the way students used pictures, text. and music to create their digital argument or the way color and arrangement were used in the creation of a comic book. Not surprisingly, for the paper projects, the discussion of presentation most often took the form of the number of pages required and the fact that students lacked clear transitions in their print texts.

Table 1 also shows evaluation concerns ranked fourth in both media but were slightly higher in the multimodal. All three instructors found evaluating the multimodal projects more challenging because of their lack of experience with multimodal assignments. Rachel's strategy to deal with this challenge was to create a detailed rubric that allowed her to focus on the elements she expected students to master in the assignment rather than allow herself to get caught up in the bells and whistles the technology offered. Allison and Michelle also created a rubric for the assignment that 
evaluated the compositions as unsatisfactory, satisfactory, or excellent. But because they were teaching the same assignment at the same time, they also met to look at and discuss the projects once they were turned in. They found this collaboration especially useful with projects they considered to be on the borderline between unsatisfactory and satisfactory or satisfactory and excellent. Despite the fact that evaluating the multimodal project was more challenging for the instructors. they also thought it was more "fun" because looking at these projects was so different than the print texts they were used to evaluating.

Finally, although much of the research into multimodal composing has focused on student enthusiasm and everyday literacies, Table 1 indicates very little discussion of these elements by the three instructors interviewed. For the most part, the instructors focused their evaluation of the assignments and the modalities as well as their evaluations of the projects themselves on issues that compositionists consider part of advanced rhetorical and literacy practices.

\section{Instructors Transfer Vocabulary from Print Texts to Teach Multimodal Texts}

One of the first issues that became obvious from the interviews was that the instructors were able to transfer print text vocabulary to the multimodal texts. In fact, these instructors used their knowledge about teaching print texts as the basis for teaching multimodal texts. This was especially apparent in the language they used when talking about both assignments. For example, since all three instructors assigned arguments for both projects, there was a great deal of discussion about the need for an "assertion" and "evidence" in the compositions. These terms were used the same way throughout the interviews regardless of the medium in which the particular composition was produced. 
When articulating her criteria for evaluating the multimodal compositions, Michelle said, "I first looked for what their assertion about literacy was" and "the project was more successful because they did have an assertion and some more support." Similarly, when discussing the project 2 papers. she again focused on the need for an assertion: "Even though we did quite a bit with creating an argument - what is your argument. what is your assertion about literacy going to be. how are you going to examine your data about this person this time - some of them still did not quite understand that they needed a central assertion that they should stick to."

Allison went so far in her evaluation of the project 1 multimodal assignment to compare it to a traditional paper and the type of assertion a reader would find in it: "One thing I've tried to do with my [evaluative] comments is compare [the assertion in the multimodal text] to what they know about writing traditional papers. and so for the person who didn't have an interpretation. I said this would be like you having a paper where you gave me a bunch of details but you had no thesis." for all three instructors, having an assertion was important for the composition. regardless of the medium.

Likewise. the discussion of evidence did not change due to the medium of the project. For instance. in the first project of the semester. a print text composition. Rachel asked her students to draw on personal experience to back up their assertions. She said, "A lot of them used this opportunity to talk about their high school experiences, which is not very far away for them." Michelle and Allison. whose first projects were multimodal. asked students to use interviews with friends or family members to back up their assertions about literacy in this initial project. 
However. for all three instructors. the stakes were higher for the second project. Students in all three classes were expected to incorporate some kind of outside textual evidence in the second project. This appears to be the result of the instructors expecting more from the students because they had been exposed to more of the readings in class and more class time had been spent on how to incorporate outside sources into the project. Because of this greater exposure. Michelle expected her students in project two to make "some conjectures in their papers about how their observations [in the first project] related to the theory that [the class] had looked at." As Rachel moved her students into project two. a digital argument. she said that one of the things that went well with the assignment was the time spent "looking at the internet and deciding what were good forms of support and what were not. They were trying to differentiate between unreliable and reliable internet sources." Thus. the incorporation of textual evidence to back up the compositions "assertions was a necessary clement in each instructor's second assignment.

Being able to actually use these sources effectively to make an argument also took on greater importance. When discussing their evaluations of the projects. all three instructors valued a student`s ability to use the source material well. Rachel describes one especially good multimodal project this way. "It was very tight. There was not a lot of unnecessary information. They did a good job of incorporating graphs and statistics." Allison referred to using sources well as one of the main components of a strong project two.

Another element that is closely connected to evidence and also appears to be tied more to the assignment placement rather than the medium used is the specificity of the 
argument. Michelle and Allison both expect students to use evidence from the class readings to narrow their argument about their profile person's literacy practices in the second assignment, a print text. Michelle said.

I spent more time on the specific argument on the second one. I was far more general in the multimodal ... In the second one we actually got into groups and they answered a discussion board question one morning where I said. 'Think about some of the things you thought about when you gathered your data. Write two of them out and then think about how you could turn that into a thesis statement. Talk about starting your essay with a rough thesis statement in mind.

Likewise, Rachel's second assignment which she called a "digital argument" required a great deal of specificity. She explained the assignment like this: "the students were asked to decide on an action they wanted the group to take-to identify . . . a specific action, to narrow that down to a pretty narrow question. to find evidence from which to convince an audience to take that action. and to present a counter argument---within the format of a digital argument. A proposal argument - to propose something." So evidence, along with having a tight, focused assertion. became the most critical elements to the second project regardless of the medium in which it was composed.

\section{Instructors Used Vocabulary from Print and the Physical World to Discuss Presentation Choice}

As Table 1 illustrates, presentation was mentioned almost twice as often in the multimodal projects as it was in the paper projects ( $13 \%$ in paper versus $23.5 \%$ in multimodal). Within the paper projects, discussion of presentation was limited and usually centered on the number of pages required or a lack of transitions within the text. 
Within the discussions of multimodal texts. presentation usually focused on the affordances of the medium (what the capabilities of a particular medium were) and the ways students did or did not use those affordances. Surprisingly. the instructors seemed comfortable discussing presentations which relied heavily on only one medium. such as images with a small amount of supplemental text or an audio presentation. but as the mediums became more layered. the instructors had difficulty discussing the rhetorical aspects of the texts and instead used descriptive terms from the physical world or referred to the students" "creativity." which served as an ambiguous. catchall term.

Allison illustrated some of the difficulties presentation posed for instructors when she said.

I think there is less writing in [the multimodal compositions] even if they are making the same kinds of moves in organizing their slides or video or whatever. There is less written text in there to evaluate. So I guess that would be one of the challenges. Not feeling like you can focus on the print text | as much in the multimodal. There are other issues that you have to consider: the word isn't the only thing communicating or conveying the message. Does that make sense?

While Allison knew that the print text was not the only element of the multimodal projects that she could evaluate. she had difficulty articulating how the evaluation of the other elements would work. This was not an issue as much for compositions based mainly in one mediurn.

Instructors felt fairly comfortable discussing projects with fewer affordances and often transferred print text language to describe those affordances. One of Allison's 
students`projects was a travelogue illustrating the profile person`s trip to Russia and the cultural literacy we often take for granted. Allison describes the medium`s affordances this way: "She had a lot of images. like clip art she had gotten from the computer and things that really helped to illustrate her points where she didn`t have to have a whole lot of text." Moreover, sometimes Allison was able to bring print concepts to bear. "She just had to have some headings. captions. things like that." The affordances of multimodal projects also allowed for more traditional academic forms of evidence such as graphs and statistical charts. In Rachel's evaluation of a digital argument. she explained there was also room for more commonly accepted types of textual evidence: "They did a good job of incorporating graphs and statistics and not just highly emotive pictures. They appealed to the logic as well as the pathetic appeal."

Yet as the layers within the texts increased. the instructors began to have difficulty articulating their evaluations of the texts. While they seemed comfortable talking about images replacing text such as in the travelogue. they were less successful discussing the multiple layers which provided reinforcement for the text. For example, Michelle was impressed with the way a student used the affordances of a video to illustrate her grandfather's everyday literacies but could not pinpoint the reasons for its effectiveness: "The pictures lent themselves to an understanding of her grandfather, a combination of the pictures and the text and even the music. It sounds funny but even the music lent itself to envisioning her grandfather using similar mental skills to do the tasks that were non-print" (emphasis mine). Michelle could not clearly articulate why the multiple layers of pictures. text. and music work well to create an understanding of the student's grandfather. but she knew that they did. 
When commenting on the students abilities to compose in a variety of mediums, Allison became enthusiastic: "But it was really cool for me to see the way they were able to kind of navigate through the mediums. I don't know that I would have thought to have done some of the things they did." Allison was impressed with the ways her students were able to layer the mediums in original ways, yet she could only vaguely describe it as being "cool."

The instructors made similar moves when discussing aspects of the projects that were less successful. Rachel described one digital argument that did not turn out well: "It was just the presentation. It wasn't the idea, and it wasn't even the research; it was just the way it all came together in the final product that made it kind of weak." While she had previously discussed the way the argument and evidence both worked for the composition. Rachel had a more difficult time indicating exactly what it was that kept the presentation from working.

Another area where the instructors had difficulty articulating issues with their students" texts was when the students tried to translate information from the multimodal medium to a paper text or vice versa. Michelle described one student`s attempt to translate her multimodal project 1 into the print text project 2 :

In the paper, she translated pretty much directly with even more detail, so there was a beginning thesis statement that said. 'my grandfather exhibits many literacies. And then [later]. "he exhibits mechanical literacy because he works on cars and truck and tractors: he works on this; he works on that. He also exhibits agriculture literacy: and she never makes strong connections to how that was a literacy — why we should call that a 
literacy or anything. It was just this long list. which probably the direct translation is what she was doing in the multimodal project, but it didn't work in print. which I found was kind of interesting. It wasn't as effective an argument.

Michelle seemed surprised that the student could not just boil down her multimodal assignment to create the print assignment. but rather than clearly articulating her realization that the two mediums did not translate. she vaguely described it as "kind of interesting." which is reminiscent of Allison"s use of the word "cool" to describe the students" composing process. Both "cool" and "kind of interesting" lack any kind of academic inference and indicate that the instructors found the presentations 'issues to be unexpected and beyond what their academic vocabulary to discuss the texts could describe. It is also interesting to note that the problem of translating the projects went both ways-from multimodal to print but also from print to multimodal.

One reason this issue of translation may have occurred was because the instructors seemed to use vocabulary from the three-dimensional physical world when describing the multimodal compositions rather than the academic language they were able to use for the print texts. In an earlier quote. Allison used words descriptive of the physical dimension to talk about how the students were able to "navigate through the mediums." She used this physical description as if her students were taking a trip through unknown or unsafe territory. This physical concept of navigation may not only reflect her lack of an academic vocabulary to discuss the presentation but may also represent her need for some type of map to guide her through the mediums. 
Rachel used these physical descriptions throughout her discussion of presentation issues in the multimodal compositions: "They had really heary: text on the slides which the narrator read right off of the slide. The presentation was just very flat, so they didn't really make use of the affordances they had in order to really make the argument and the evidence more compelling" (emphasis mine). Rachel described the project 's dimensions - as if the layers added by the affordances of the medium made it a threedimensional physical object with weight and shape. She did this again when discussing the limits of the presentation in print text assignments when compared to multimodal: "Because you re dealing with fewer affordances [in print]. there"s less room to push those creative boundaries." This time. Rachel's use of the word "boundaries" denoted a physical restraint the medium placed on the students. Overall, the instructors were far less adept at using academic vocabulary to discuss presentation in the multimodal projects.

\section{Evaluation Was a Source of Anxiety in Multimodal Composition Due to the Perceived Student Investment}

Evaluation of the multimodal compositions proved to be a source of anxiety for all three instructors. Because this was the first time the instructors had evaluated a multimodal assignment. there was more planning and preparation time involved than in the traditional print texts. Collaborative grading sessions helped somewhat to ease the tension of the evaluation. Allison explained. "[Michelle and I] took some problem multimodal projects and also some of the really good ones and showed them to each other and talked about them and how we would both evaluate them and why. We didn't do that with [the project 2 print text]. I guess because we were newer to the multimodal stuff and less confident in our abilities to judge it correctly. " While these tactics served to somewhat alleviate the tensions surrounding the evaluation process. the evaluation was 
complicated because of perceived stlident investment which occurred in two ways: the time spent working on the compositions and the risks students took by creating projects that had a personal or emotional element to them. Interestingly, even though the enthusiasm students have for creating multimodal compositions has generally been described as a good thing. we also see in the following examples that it can create uncertainty for the instructors who often struggle for the appropriate language to describe the projects.

\section{$\underline{\text { Time }}$}

Rachel. who did not have someone with whom she could collaborate on the assessment, relied instead on a focused rubric to keep her evaluations impartial. She said, "I had trouble with the multimodal projects - just not giving everyone a good grade because they did something different and tried really hard." As Rachel exhibited in this quote, the perception that the students were doing "something different and tried really hard" had an impact on how all of the instructors wanted to assess the multimodal projects. She went into even more detail about the weight of the evaluation process on her conscience:

I didn't feel comfortable just slashing and burning somebody`s project because overall. with the exception of a few slackers due to group dynamics. they all worked really hard and it was pretty high stakes in terms of the work and the hours they put into this. I had several who came when I held the lab open ... and I would have felt uncomfortable giving them really bad grades ... So that was the biggest challenge - just feeling 
like I could not come down really hard and judge these really heavilythere was just too much investment on their parts. I think.

Michelle also allowed the amount of time she perceived that students had spent on the multimodal projects to be a source of anxiety in her evaluation: "The difficulty of [evaluating a multimodal text is] detecting or sensing or feeling a difference between a student who put hours and hours and hours of work into an unsuccessful project and students who didn`t [spend as much time but still had a successful project], and I could tell - which is sort of about non-tangible things. It's about just feeling." And the angst that Allison describes is probably something to which many instructors can relate:

Well. I mean. honestly you do feel like, oh my gosh. this person has probably put so much time into this. You know? Like the one student who didn't actually profile the person but had this really kind of creative thing about growth and the literacy cycle. I know that took a lot of time to find all those images and get them in there and put music to it. but it didn't meet the assignment's requirements, and so of course I have in the back of my mind, 'Okay, many of them weren`t excited about doing a multimodal project anyway. now I'm going to be assigning a grade they re not going to be happy with.' So that's a bit of a struggle thinking about how they're going to respond.

While time is rarely a factor in their discussion of the print text evaluations, all three instructors found it to be a significant source of anxiety in their evaluations of the multimodal projects. 


\section{Personal Risk}

However. time is not the only investment that the instructors perceived the students made in the projects. Table 1 reinforces that the instructors also perceived the student enthusiasm surrounding the multimodal project was higher than the print project. For the instructors, this enthusiasm seemed to translate into a personal investment on the part of the students, which the instructors perceived as the students taking risks. Even though all of the projects were arguments, the multimodal mediums caused instructors to perceive more of the students" personalities or identities coming through in their compositions. which also appeared to cause anxiety for the instructors during evaluation. Michelle summed it up best:

I think we feel that in a creative project there is more emotion attached to it. There is more of the person attached to [the composition] because of the creativity involved. I don't see logistically why it is any different but emotionally [it is]. So it was harder for me to say to someone who spent clearly a lot of time gluing and pasting something-glitter, some of them used glitter. (Sarcastically) How can I give this a bad grade; they bothered to put glitter?

Though she is being sarcastic. the heart of the problem is exposed-certain affordances seem to carry more emotional weight than others.

Michelle's interview was full of these moments where the emotional weight of the multimodal project is evident. She made the comment about one project. "[The music] was John Denver. It was country stuff. Sounds crazy. but I found it very powerful and very effective. There was even some of [her grandfather"s/ own guitar picking." In 
another, it was a subject's art work on display: "It"s about his friend who is an artist, and his dorm-room literacy is his art-work, and it is amazing art-work . . and he pans the camera over his friend"s work, which is stunningly amazing ..." Though it "sounds crazy" even to her and was never more fully explained. Michelle seemed to find these personal elements of the compositions to carry more weight than any element that was discussed in the print texts she evaluated.

The perceived risk the students took with their emotional investments similarly seemed to impact Rachel who discussed creative choices in terms of personal risk. Rachel explained.

It's hard to give them a really bad grade for students who were stepping out of their comfort zones ... I think whenever you have an aspect where you're asking a student to be more creative, and we are asking students to be more creative in these types of assignments. I think we encourage creativity in writing. but we do it within very strict parameters because of the way we ve been taught and the expectations are much more regimented. Even within creativity I think the expectations are different. So this type of assignment -l feel the students take the opportunity to be more creative maybe than they do in a text based assignment. And I think they"ve been punished a lot for taking too many risks traditionally. Thus, even though instructors want siudents to be invested in their compositions, the personal investment can sometimes translate into perceived personal risk for the instructors evaluating the compositions. This feeling of the students taking "risks" and "stepping out of their comfort zones" seemed to carry as much weight for Rachel as the 
personal elements that Michelle noted in her students ${ }^{*}$ projects and ultimately made evaluating the multimodal compositions a stressful process for all three instructors.

\section{Issues of grammar, mechanics, and citation of source documents were ignored when assessing the multimodal compositions.}

Just as interesting as the elements on which the instructors focused are the ones they ignored. For example. they frequently ignored elements of the compositions for which they would typically deduct points in the print texts. Allison explains why she did not count off for mechanical errors in the multimodal compositions:

There were some [issues with grammar and mechanics], but I was less likely to comment on those in the multimodal than I was in the print essays. For instance, one student splashed 'literacy's' throughout his multimodal project. I didn't comment on it. I tried to highlight it in my own comments to that student to spell it correctly - to model it-but I didn"t call attention to it. whereas in their papers I did. In their papers, I marked on their drafts and tried to explain some of the concepts. In the multimodal compositions. there were bigger issues even than [grammar and mechanics that] we needed to deal with first. That wasn't the top priority for me. Even when I am reading the [print text] essays that is not my main priority. but I was more likely to comment on it in print.

Ignoring such glaring mechanical errors was common to all three instructors. Many of the multimodal projects had multiple errors-misspellings appeared to be the most common, yet the instructors seemed to just jgnore them for the most part.

However, possibly even more surprising was how the instructors appeared to ignore failure to cite source documents and include parenthetical citations within the multimodal 
projects. On very rare occasions. the students ran credits at the end of the composition which looked similar to a Works Cited page, but often there was either no citations at all or just the URL of the website used or the name of the band and song they had used as background music. There was never any attempt to cite songs or pictures according to MLA or any other citation standards. The lack of parenthetical citations also made it difficult to know where students had obtained specific information and whether or not that information had been directly quoted from a source or synthesized into the argument in the student's own words. The narrator might cue the viewer with the introduction, "According to the CDC ..." but that was the only clue to the information's source. When asked about why parenthetical citations were not required. Rachel explained that is wasn`t appropriate for the digital argument genre: "In documentaries or commercials or public service announcements, you don`t see parenthetical citations on the screen. They aren't expected to be visible to the viewer. so I didn't think they were necessary for the students' digital arguments." So even though instructors require a use of outside sources for the multimodal compositions, they often appear to ignore issues of grammar and mechanics and proper citation of the sources in this type of composing.

\section{Conclusion}

Through these interviews. it is clear that the instructors were often able to draw from their experiences teaching print texts to teach multimodal composition when they were discussing aspects of argument. evidence. and elements that were traditionally print text elements. Much of the vocabulary surrounding the rhetorical practices of first-year composition appeared to be transferable for their teaching purposes as instructors used words such as "assertion" and "evidence" in the multimodal assignments to mean exactly 
the same things they meant in the print assignments. According to research on knowledge transfer, the instructors have an awareness of the ways the rhetorical terms transfer from print to multimodal composition because the instructors see these aspects of the compositions to be similar contextually even though the mediums may be different (McCarthy, 1987: Beaufort. 1998: Ford. 2004).

However, their discussions of presentation, including the affordances of the mediums. more often drew from elements of the physical world because of their lack of a rhetorical vocabulary surrounding issues of presentation. In the multimodal projects, text became "heavy." presentation could be "flat." and the layers of affordances provided by the medium were to be "navigated" because they did not contain the creative "boundaries" of the print text projects. Cynthia Selfe (2004) anticipated this problem with compositionists who have been educated with a focus on print texts. She argues for increased education in visual rhetoric among these instructors because "faculty may feel that they lack the analytical skills they need to conduct serious study of these texts. an effective vocabulary and set of strategies for discussing the structure and composition of new media texts ..." (p. 67). This physical vocabulary seemed to give the instructors a way to approach the element of presentation in the multimodal compositions which was a less familiar element to them because of the difference in definition from print, but it still appeared to contribute to some of the discomfort instructors expressed when discussing the specific problems with the multimodal presentations. Also. it is interesting to note that the language of the physical world instructors used to describe presentation issues did not transfer to the students in their description of presentation issues. 
Perhaps the most surprising finding was that student enthusiasm might actually be a double-edge sword. The student's personal investment in multimodal composition has often been touted as a positive characteristic because the students become more invested and enthusiastic about working on multimodal projects. They are able to add meaningful music to a video composition or decorate their scrapbooks in ways that speak to them. They often claim to enjoy composing for the first time. Hull and Katz (2006), in their discussion of the DUSTY program (a digital storytelling program for unrepresented youths in Oakland, $\mathrm{CA}$ ) even claim that multimodal composition can have the agentive power to transform struggling students into engaged and successful composers for the first time in their school careers. However, the price that may be paid for the student enthusiasm is instructor anxiety during evaluation due to the increased time and amount of risk the instructors perceived went into multimodal projects. While all instructors want their students to be enthusiastic about their compositions, the instructors should be able to be equally comfortable and confident in their evaluations of those compositions.

In Chapter 4, I analyze data from five student interviews to determine where their perspectives about print and multimodal composition converge and conflict with their instructors" perspectives. 


\section{CHAPTER 4 STUDENTS COMPOSING IN MULTIPLE MODES: THE PROCESS OF ACCUMULATING ACADEMIC LITERACY}

Chapter 4 examines the results of five student interviews about the process of creating multimodal compositions compared to print compositions. This chapter builds on the results of chapter 3 where I found the instructors transferred print text language to their teaching of the multimodal projects but had difficulty discussing issues unique to multimodal composition such as presentation. They also felt more anxiety when assessing the multimodal projects due to the additional time and personal investment they perceived students made when composing multimodally.

Chapter 3 examined only the instructor responses. and it is possible that the instructors were overly optimistic about the concepts the students were able to take away from the multimodal composition assignment. The instructors transferred many academic literacy concepts. but were the students similarly able to make those academic literacy connections between their print texts and multimodal texts? Were the instructors simply reading into the products without the students really having made those connections? Also, the instructors had difficulty discussing issues of presentation in the multimodal compositions. Would their inability to articulate those rhetorical principles affect the ways their students talked about presentation? Would the students already have so much experience reading and creating multimodal projects outside of the classroom that they would not need their instructors" guidance through issues of presentation? 
Finally, assessing the multimodal compositions was a source of anxiety for the instructors due to the amount of time and personal investment they perceived went into the projects. Did the students actually invest the amount of time the instructors perceived they did? If so, did they resent the amount of time necessary for composing multimodally or did they enjoy composing in the new modes enough to make up for the extra time involved? Did they express problems with their instructors’ assessments of their projects? Did their personal investment in the projects make them resentful of revision suggestions?

This chapter's goals are to determine whether students have some of the same difficulties discussing issues of presentation as their instructors did and to see how the students understand the relationship between print and multimodal composition by comparing the student and instructor responses. Do the students understand the multimodal assignment goals in the same way their instructors do and adopt some of the same rhetorical goals or do the students see it as mainly "fun"? Researchers claim one reason to include multimodal composition in the first-year composition classroom is because students are already familiar with the technology and use it on a routine basis to create projects for websites like YouTube or MySpace. Is this the case with the students interviewed or is the technology used to create digital arguments and audio/video essays new to them?

As described in Chapter 2. I interviewed five students in Michelle, Allison, and Rachel's first-year composition courses asking questions regarding their experiences composing multimodal and print text assignments after they had completed both assignments. Will. Beth, and Sarah were Honors' Program students taking English 105 and created their multimodal compositions first. followed by the print composition. These 
students were allowed to choose their mediums for the multimodal project. Emily and Pam were students in English 102. the second course in the two semester sequence. They created the print text first and then the multimodal text which was required to be a "digital argument" created using MS Movie Maker. See Chapter 2 for more information about the students and assignments.

Resuits of chapter 4 indicate that. like their instructors. students were able to transfer print text vocabulary to their multimodal compositions, but they did not have an effective vocabulary for presentation issues. This resulted in a "more is better" approach to multimodal composition. Results also indicate that students are hyper-aware of audience in their multimodal compositions but that awareness does not transfer to the print texts they compose.

\section{RESULTS}

\section{Overview of Student/Instructor Similarities and Differences}

Table 1 overviews the types of themes students raised and illustrates that, much like the instructors. the students were most concerned about issues of assertion and presentation. The students mention issues of assertion $55 \%$ of the time when discussing multimodal composition compared to $75 \%$ of the time for their instructors. Issues of presentation in the students ${ }^{\prime}$ interviews are similar to that of their instructors $(56 \%$ in students versus $51 \%$ in instructors) in the multimodal interviews. Both groups place less emphasis on presentation in the print text interviews. yet it appears to be a greater concern for the students $(23 \%)$ than it is for their instructors $(10 \%)$. One noteworthy difference between the student and instructor interviews is the lack of focus the students place on evidence compared to their instructors. Students focused on evidence less often 
than their instructors. The theme of evidence had the third highest occurrence in instructors' multimodal interviews (37\%) and the second highest occurrence in the print interviews ( $45 \%$ ). However, students focused on evidence only $25 \%$ of the time when discussing their multimodal texts and only $21 \%$ of the time with their print texts even though both compositions were required to have some type of outside evidence. Also, the students talk about evaluation less than their instructors and process more which makes sense because the students focus is on composing the texts rather than evaluating them. These issues will be discussed in more detail below.

Table 1: Percentage of the time each theme came up in instructor \& student interviews

\begin{tabular}{|c|c|c|c|c|}
\hline Themes & $\begin{array}{l}\text { Multimodal Text } \\
\text { Occurrences } \\
\text { (Instructor) }\end{array}$ & $\begin{array}{l}\text { Multimodal Text } \\
\text { Occurrences } \\
\text { (Student) }\end{array}$ & $\begin{array}{l}\text { Print Text } \\
\text { Occurrences } \\
\text { (Instructor) }\end{array}$ & $\begin{array}{c}\text { Print Text } \\
\text { Occurrences } \\
\text { (Student) }\end{array}$ \\
\hline $\begin{array}{l}\text { Assertion } \\
\text { (Audience) }\end{array}$ & $75 \%(n=75)$ & $5 \overline{5 \%(n=60)}$ & $58 \%(n=54)$ & $63 \%(n=30)$ \\
\hline Presentation & $51 \%(n=51)$ & $56 \%(n=61)$ & $10 \%(n=19)$ & $23 \%(n=11)$ \\
\hline Evidence & $37 \%(n=37)$ & $25 \%(n=27)$ & $45 \%(n=4 I)$ & $21 \%(n=10)$ \\
\hline Evaluation & $32 \%(n=32)$ & $17 \%(n=19)$ & $20 \%(n=18)$ & $8 \%(n=4)$ \\
\hline $\begin{array}{l}\text { Technology as } \\
\text { Obstacle }\end{array}$ & $15 \%(n=15)$ & $15 \%(n=16)$ & $0 \%$ & $0 \%$ \\
\hline Process & $11 \%(n=11)$ & $40 \%(n=44)$ & $10 \%(n=9)$ & $73 \%(n=35)$ \\
\hline $\begin{array}{l}\text { Student } \\
\text { Enthusiasm }\end{array}$ & $8 \%(n=8)$ & $13 \%(n=14)$ & $0 \%$ & $6 \%(n-3)$ \\
\hline Total Episodes & 100 & 109 & 92 & 48 \\
\hline
\end{tabular}

*because each episode could be coded multiple times. percentages add up to over $100 \%$

\section{Students foreground audience when discussing multimodal composition.}

For the instructors. having a clear assertion was the theme most often discussed in their print text interviews (58\%) and multimodal composition interviews (75\%). This message of having a clear assertion appears to have transferred from the instructors to the students. The students all seemed to understand that having a clear assertion was necessary for a successful project---regardless of the composition`s mode. However, the students often discussed the assertion in terms of the message`s impact on the audience- 
something implied but not overtly stated by the instructors. For this reason, the student and instructor interviews were coded for occasions when audience is mentioned within a discussion of assertion.

The students ${ }^{*}$ comments about assertion in their discussion of the multimodal compositions are so completely tied up with audience that audience and assertion become almost indistinguishable. Pam discusses how the audiences" understanding of the composition"s assertion is critical to having a successful composition. "The message of the overall argument is the most important part. Other things contribute [to the essay's success] but overall we re arguing one point and if that point is not understood then everything else falls apart too." Beth similarly shows how students conflate assertion and audience:

The point is not necessarily making someone believe what you believe .. but making them think about something different. So they're not just reading some generic piece of information. It leaves a lasting impression on them, makes them think. makes them associate what you've done with other things they've seen but now they're seeing it in a different way. Will also sees an assertion as an element that is necessary for the audience rather than just an element to check off of a rubric: "Writing is not just rambling along with information; it"s having relevant information ... If you are talking to a teacher or a business associate or a colleague, you want to have a point when you talk ... and that point should be easy to see, like a thesis statement - it should be obvious and relevant to your audience." Sarah explains the planning required to get the appropriate message across to the audience: "You really do stop and think why you are choosing these different modes and 
how you are going to express your message to the audience without it being just a bunch of pictures put together or a five-minute video about whatever." Overall, it appears difficult for the student to discuss the assertion of their multimodal compositions without mentioning its effect on the audience.

Table 2 shows that $93 \%$ of students ${ }^{`}$ statements about assertion also mention audience compared to only $24 \%$ of the instructors statements. This difference in the focus on audience could have a couple of explanations. First. it may show that the instructors simply have a richer vocabulary and sense of the principles surrounding argument. At one point. Rachel refers to a student's use of graphs and statistics along with photographs as proof that the student was using logic as well as pathos to make his argument. Her discussion of logic and pathos refers to how the audience will perceive the argument, but she has an academic vocabulary with which she can discuss the project. Second, the students" focus on audience may indicate that talking about audience gives them an entryway to talking about argument as they are focused on the process of composing their multimodal essays.

Table 2: Percentage of Assertion comments that discussed audience

\begin{tabular}{lrcrr}
\hline \multicolumn{1}{c}{ Themes } & $\begin{array}{c}\text { Multimodal } \\
\text { Text } \\
\text { Occurrences } \\
\text { (Instructor) }\end{array}$ & $\begin{array}{c}\text { Multimodal Text } \\
\text { Occurrences } \\
\text { (Student) }\end{array}$ & $\begin{array}{c}\text { Print Text } \\
\text { Occurrences } \\
\text { (Instructor) }\end{array}$ & $\begin{array}{c}\text { Print Text } \\
\text { Occurrences } \\
\text { (Student) }\end{array}$ \\
\hline Assertion & $\mathrm{n}=59$ & $\mathrm{n}=28$ & $\mathbf{n}=50$ & $\mathrm{n}=23$ \\
$\begin{array}{l}\text { Audience in } \\
\text { Assertion }\end{array}$ & $\mathbf{n}=14$ & $\mathrm{n}=26$ & $\mathbf{n}=3$ & $\mathbf{n = 3}$ \\
Total \% & $24 \%$ & $93 \%$ & $6 \%$ & $13 \%$ \\
\hline
\end{tabular}

Table 2 shows that both instructors and students - but especially students'discussions of audience-related issues drop dramatically when they discuss the print texts. When discussing their print compositions. students often talk about assertion abstractly in 
terms of process. They are relatively disinterested in their messages' impact on an audience they see as academic. This distinction is what Linda Flower (1979) described as the difference between "writer-based" and "reader-based" prose. When composing multimodally. the students are "reader-based:" they are deliberately communicating a message to the audience. Yet when composing a print text. the students become "writerbased" and see the text as written "to himself and for himself" (19).

For example. Emily focuses on the process of creating her paper text's assertion, "For my paper's assertion. I was forced to draw parallels between the two arguments I was making." She never mentions who she is drawing the parallels for-the audience is in no way a part of her focus. Sarah. who had talked about her multimodal composition as being a text that "people can look at and understand the message I am conveying" and who had a clear focus on the audience: "I think it is important for the student to consider the audience they are trying to reach." discusses the first draft of the print text as a document that "didn"t exactly have a clear place for my argument." Sarah moved from a focus on whether or not the audience received her message in the multimodal composition to a focus on the space for her argument within the print text. She never mentions an audience when referring to her print text. Beth. who "tried to explain to people how important [her grandfather"s literacies] were" in the multimodal composition. looks at the assertion in the print text version of the same topic as an idea she took from a literacy scholar and then "crafted for my own use, for my own means." Like Sarah and Emily, Beth never considers any kind of an cutside audience. The focus shifts from how the argument will be received in the multimodal text to how it is created in the print text. 
One reason students discussed audience more with multimodal composition may have been because they envisioned a broad audience versus the print compositions where they envisioned an audience narrowly focused on the instructor. This narrow academic audience is illustrated by Will's comment: "I basically had the same thesis [for both texts]; it was just the difference getting from my ideas to conveying them to the teacher." In contrast, the students never mention the multimodal composition's audience as being their instructor. It appears they never assume the instructor is their only or even their main audience. They seem to regard the multimodal composition`s audience as much more broad and general. In fact. Beth shows the extent to which students saw the audience for multimodal as non-academic: "I think [scholarly research inserted into the multimodal composition] would have taken away from the overall emotion of the presentation." Thus, for her, the academic audience for the multimodal composition is less important than reaching a more general audience whom she intuits would not appreciate the inclusion of scholarly research (even though it was a requirement of the assignment).

\section{Students perceive that print texts achieve depth but the multimodal texts allow them a place to practice conciseness.}

Because of the different audiences the students envisioned for the print and multimodal compositions. the students saw different goals that affected the form and style of the compositions. Unlike the multimodal texts, which had a general audience, the students appeared to equate the print texts with "academic writing" and being "wordy." They found it difficult to replace the ideas they thought they had been able to convey in the multiple layers they created in the multimodal compositions into words in their print texts. They repeatedly made statements such as. "[The print text] seemed a little more in- 
depth just because I had to use more words to express it" or "You have to try to be a little wordier [in the print text] because sometimes that 's what a lot of people think is associated with academic writing." They often describe this type of composing as being difficult because it requires more thought than multimodal composing. For instance, Sarah sees the process of moving from multimodal to print as difficult because she has to replace pictures with enough words to fill up the page requirement:

The print text was more difficult because I couldn`t rely on pictures to make some sort of point. I had to explain it in-depth. In that process, I had to think more about what I was writing." She continues. "It was difficult finding words to use [for the print essay] ... I wouldn`t say that I tried to fill up space but trying to make the paper extend for 6-8 pages was tough. I mostly had to expand on the ideas that I had just scratched the surface with in my multimodal essay.

Just as the students discuss the print texts as places where they needed to be "wordy" to replace the ideas they conveyed through other mediums in the multimodal texts, they discuss the multimodal essays as places to practice concision. Will explained the difficulty of being concise in the multimodal composition. "It took a bit of time trying to figure out how to make things concise [in the multimodal essay] ... Michelle told us we needed to keep them to three to four minutes to keep the audiences' focus, but that was hard for me." Pam similarly said that concision was one of the skills she learned from composing the multimodal essay: "I think it was really important for me to realize I can only include the important information ... and keep out the useless information. There's just no room [in the multimodal essay] for things that do not matter." And Beth 
called the process of gathering the information to create the multimodal essay to be "brief but informative ... There were things I wanted to include but I didn"t have room or they would have been swamping the thing and the audience would have lost interest." Although the instructors never mentioned a focus on concision in their multimodal or print text interviews, the students seem to make a connection when composing multimodally between having a clear assertion the audience can follow and being concise.

\section{Students see issues of presentation as intuitive.}

As previously mentioned, students approached the presentation of the multimodal projects as an intuitive process. In other words. they lacked the clear guiding principles necessary for a rhetorical discussion of presentation so instead they focused on their past experiences. Thus presentation became more about things they had internalized than principles they had abstracted and consciously attempted to apply. It is not surprising that students relied on their intuition given their instructors were unable to give them a great deal of guidance on issues of presentation, but what is interesting is that these students relied on prior models they had seer and a "more is better" approach. For example, Will used television news programs to shape his ideas about multimodal presentation: "I tried to mimic Dateline. I watched a couple of those on Sunday night and tried to do that." From viewing Dateline. Will. whose profile person was from Kenya, learned that his presentation would be most effective if he could find some "ethnic tribal music" to play in the background while playing pieces of the interview along with his own narration. This reliance on models familiar to the students, like a television news program, rather than abstract rhetorical strategies learned in the 
composition classroom is reinforced by research on knowledge transfer from Julia Dyke Ford (2004). Ford explains that students tend to depend on "model-based tactics, formats, and templates" when they are composing in a new context and those tactics, formats, and templates are what "guide their rhetorical decision making" (p. 310).

Will's decision in this situation shows both the benefits and drawbacks of the intuitive approach. For the composition, he was "arguing something [Deborah] Brandt wrote about, that literacy can be used as a means to improve yourself socio-economically. And I argued that my friend from Nairobi. Kenya wanted English literacy to make a better life for himself." Although Will's intuitive choice to add music to the composition was good, the music he chose seems questionable. The "ethnic tribal music" that Will ran under the track of his own narration and interview with his profile person may have enhanced stereotypes and undermined the presentation`s ethos. He says he chose that music "because people associate that kind of stuff with Kenya." If Michelle had been more comfortable discussing the rhetorical issues of presentation with her students during class. Will might have been challenged to question his choice. Why was what he called "ethnic tribal music" an appropriate background music for his argument? Did he ask his profile person if he was from a tribe in Kenya or did Will just work from the assumption that his audience would associate this music with Kenya? If the class had spent a day discussing the rhetorical effects of their presentation choices. Will might have instead turned to the music his protile person listened to when he was running or music that was in some way important to the profile person rather than something which appears to enhance the negative stereotype that all Kenyans come from an illiterate tribal culture and 
which ultimately does nothing to enhance the audience's understanding of Will's profile person.

The intuitive approach was also problematic for Sarah who explains that she was able to be creative by layering pictures in her travelogue: "I usually like looking at pictures and trying to see what they express. If I know there is a word that I am trying to express, I will look through pictures until I see that picture and then I know that's it. People can look at that and understand what I am trying to think of." Sarah assumes that because she is able to make a specific connection between pictures and words that her audience will automatically make the same connection. But how can she be sure? Sarah has been given no rhetorical foundation by her instructor on which she can build this belief. Therefore, she is forced to rely on her intuition. and she just intuits that the audience will be able to make the same connections she has made.

This lack of a rhetorical foundation is illustrated in the multimodal compositions. For example. Heather. one of Emily and Pam's classmates in Rachel's course, created a digital argument about the negative effects of soft drinks titled. "The Liquid Candy." The video, which is approximately seven minutes long, uses a combination of text, pictures, and narration and argues for students to give up soft drinks in favor of juices, herbal drinks, and water. However. Heather's only narration is reading the text on the screen. There is no commentary when a picture is inserted and no layering of pictures and text. Below are three screens from "The Liquid Candy" which show what the intuitive approach to presentation can look like: 


\section{The Drug was used}

as a tonic and it was also used for headache remedy.

Heather narrates: "The drug was used as a tonic and it was also used for a headache remedy."
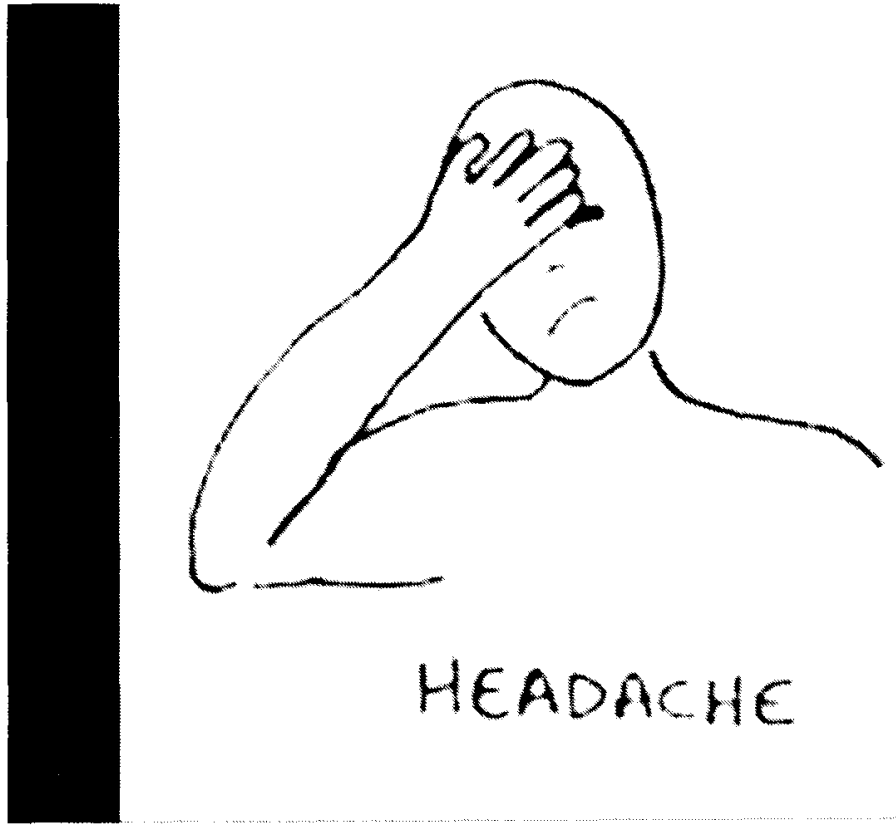

HEADACHE

Silence-no narration. 


$$
\begin{aligned}
& \text { Until } 1905 \text { the soft } \\
& \text { Drink, marketed as a } \\
& \text { tonie, eontained extraets } \\
& \text { of eocaine as well as the } \\
& \text { eaffeine rieh hul a nut. }
\end{aligned}
$$

Heather narrates: "Until 1905 the Soft Drink. marketed as a tonic, contained extracts of cocaine as well as the caffeine rich kula nut."

Rachel described the project"s presentation as "flat" and evaluated the project as a "low B" because Heather only reads the text on the screen for about four minutes. Heather's presentation is not only "flat", but it also uses the "Gigi" font which is often difficult to read during the time allotted for each screen. Ultimately. the presentation is unable to hold the audience"s attention for very long. If Rachel had been more comfortable discussing the specific elements that made Heather"s presentation "flat," Heather might have made better presentation choices that would eventually transfer to future compositions.

In contrast to Heather's flat presentation. another student in Rachel's class, Corey, adds multiple layers to the her digital argument while still showing a lack of awareness of how the medium could be most effective. Corey"s argument against tanning beds layers pictures, graphics. text, background music and a limited amount of narration. Her use of the technology is quite sophisticated with pictures overlaid with text while the music and sometimes the narration plays. 


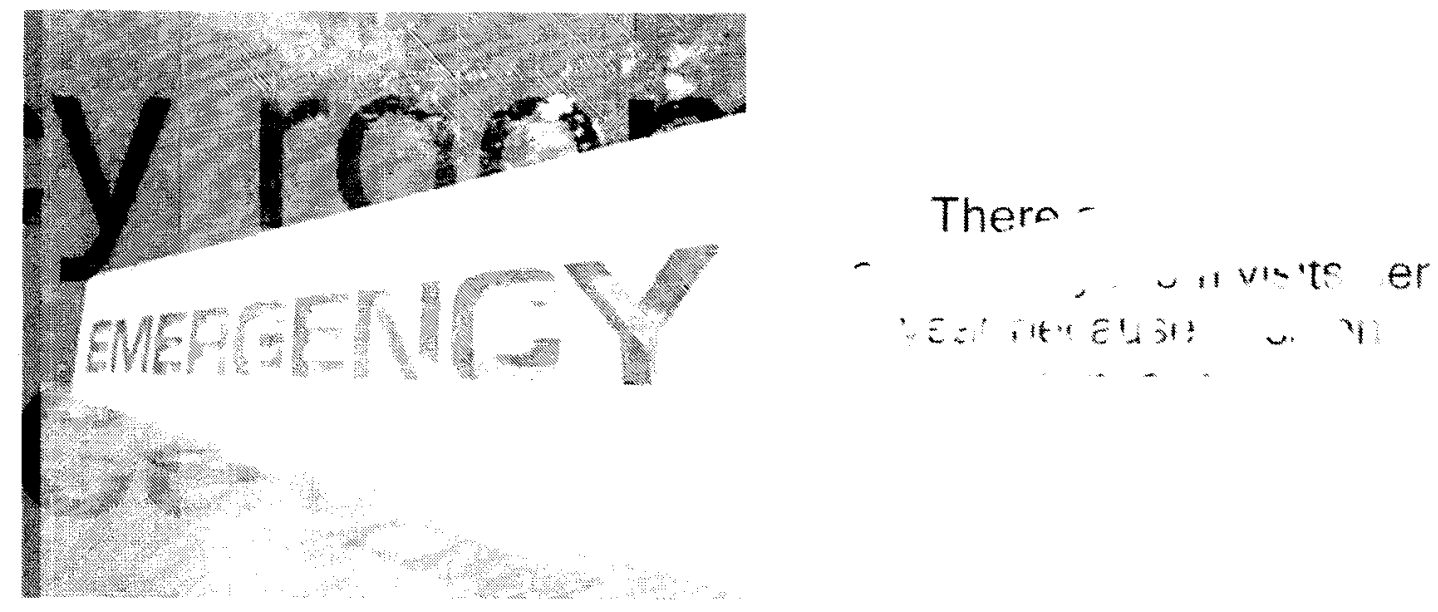

However, the pictures, which are often accompanied only by music with lyrics unrelated to the topic and without any narration, are left up to the audience for interpretation. One example of this comes in the final third of the argument. The text on the screen reads, "Skin aging and cancer have delayed effects which show up years after the exposure." This warning is followed by a series of pictures of doctors performing surgery and trays of clamps and other surgical instruments. The background lyrics from "Pain" by Three Days Grace are "Pain, without love / Pain. I can't get enough / Pain, I like it rough / Cause I'd rather feel pain than nothing at all." The message in the opening text is problematic but when that text is added to the combination of ambiguous pictures and unrelated song lyrics, the message is probably less clear to the audience than Corey intuits — an issue that might have been corrected during conferencing or peer review if Rachel had felt more comfortable discussing these issues with the class. In the absence of direct instruction on the topic. Corey, like Sarah and many of their classmates, appears to believe that the audience will use the layers provided in the composition to get the same message she does. 
Thus rather than a rhetorical examination of the students' presentation issues, the intuitive approach to presentation often lead to a "more is better" mentality among the students who thought that more layers within the composition would lead to a better audience understanding of the message they were trying to convey. Emily adds as many layers as she can to get her message across to the audience:

The [multimodal composition] was really easy to get the point across because we could use pictures and text and narration all together. I wanted to put as much as I possibly could in it--more pictures, more illustrations, more examples. I would have put video in if I could have. All of that just so the audience would come to the same conclusion I came to.

Beth even tries to skirt around the guidelines Michelle set out for the assignment in order to include more pictures in her scrapbook-like video presentation which she created by layering pictures and text in MS PowerPoint and then adding a separate audio track to be played simultaneously. She says.

I wanted to create a scrapbook because I could squeeze more pictures onto the page. Michelle said I could only use a certain number of pictures, but I took that to mean [a certain number of PowerPoint] slides. so I layered five pictures on each slide instead of one... Those pictures had a profound effect on how the reader interpreted what was going on and what I was trying to say.

Like Sarah and the others who believe a picture will evoke the same response in their audience as it does for them. Beth intuits that the audience will be profoundly affected by her pictures. Because the students were given no direct instruction about developing a 
clear sense of the affordances the different mediums offer them and how those affordances interact with the argument the students are making with the compositions, the students were savvy enough to rely on what they intuitively knew about the mediums.

This "more is better mentality" was often supported by the instructors who could not find a rhetorical rationale to discuss presentation issues. Michelle encouraged Will to add music to his video composition to make it more successful and, as stated previously in chapter 3 . she described Beth`s multimodal project as being more effective because of the way the music, pictures, and text all work together even though she could not articulate exactly how they benefited the presentation. Rachel describes Heather's essay as being "flat" and evaluated it as a low B but evaluated Corey"s multi-layered composition as an "A." So while she does not state that she encouraged students to add layers to their projects. she certainly rewards the multi-layered compositions. Overall, the "more is better" default seems to reflect a lack of critical apparatus between the students and the instructors.

The students ${ }^{`}$ intuitive approach to presentation is really no different than what was expressed in the instructor interviews. and like the instructors. the students often describe presentation choice with the catchall term "creativity." Will describes the process of multimodal composing as "creative" and says he spent more time on the project because he could use his creativity. Emily, who is an actor, enhanced the presentation with her acting abilities: "I was able to be creative in the organization of the composition. in the way I chose the pictures. in the inflection of my voice as I narrated it. There were so many options open to me." Pam describes the point where she realized her original vision for the presentation of her multimodal essay was not going to make an 
effective argument for the audience: "I got some pictures and decided to use the music from the cartoon 'Recess. I thought it would be just really creative and have lots of color-be really loud and fun." Compare this use of the term "creative" with their instructors' own statements, such as Allison who talks about one of her student's multimodal project: "I had one student who didn't actually profile the person but had this really kind of creative thing about growth and the literacy cycle ... I know that took a lot of time to find all those images and get them in there and put music to it." Both the students and their instructors appear to rely more on intuitive creativity than a rhetorical vocabulary to describe the choices the students make in the presentation of their multimodal projects.

One reason the students may have such a strong intuitive approach to issues of audience is because they recognize the pathos and the way they believe it will affect the audience. For example, at one point in Corey "s "Tanning Beds" composition, she shows a picture of a lone scalpel: the text on the next screen warns. "Death is only a matter of time..." Corey uses the text and image together to evoke fear in her audience. Although the students never specifically reference pathos in the interviews. they do discuss the emotional responses they want the audience to have. In Pam's response to questions about her revision process. she says. "I had to change some pictures and organize it in a way to be more serious" as opposed to her initial approach which was to make it "really loud and fun.." Will explains that adding music is important to audience appeal: "I played through without the music. and it was kind of boring. Music enhances it for the audience; there is just something about humans and music If we hear a sad song. we become sad. If we hear a happy song. it makes us happy. The music set the mood for my project." 
Beth expresses a similar reason for why she chose the music and pictures that she did for her project about her grandfather's literacies: "I didn"t want it to be flowery, but I did try to be creative using pictures to show different aspects of [my grandfather's] literacy. The music also helped bring a little bit of light-heartedness to the thing. I used it all to drive home that we are proud of who we are." So while the students seem to grasp the connection between pathos and audience in their multimodal compositions, what they more often appear to lack is an effective way to connect issues of ethos and logos to audience.

\section{Instructor perceptions of an increased personal investment in the multimodal compositions were somewhat confirmed.}

The anxiety the instructors expressed when assessing the multimodal compositions due to a perceived increase in the amount of time students spent working on the texts and their personal investment in the essays was somewhat confirmed by the students. Students spent an average of twenty hours composing the multimodal essays, which was typically approximately double the amount of time they spent on the print essays. For Will, this difference was even more extreme. He spent a great deal of time learning how to use Movie Maker and estimates that he spent 35 hours composing the multimodal assignment compared to only five or six writing the print essay. However, the students did not complain about the time required to compose the multimodal assignments. In fact. they often describe the experience as "fun."

Sarah likens the experience of creating the multimodal composition to the fun she had in school before projects became so traditionally academic, "I enjoyed composing the multimodal essay the most. just because it was almost elementary school stuff in a wayjust cutting and pasting. just working with my hands." Beth also portrays the experience 
as more arts and crafts than homework. "I got to play with pictures." Will describes the thirty-five hours he spent creating his multimodal composition in Movie Maker "like when you were little and you learned something new. you wanted to keep playing with it." Emily concurred that the multimodai allowed her to use her talents for something she enjoyed, "I love doing stuff like the digital argument . . . I am better at technology than I am with writing stuff for a grade. I have really poor sentence structure and poor transitions ... I loved to just play with Movie Maker." So this group of mostly honor students never begrudged the time spent on the project. Instead they are enthusiastic about creating their compositions, and after the time spent learning the technology, Will even went on to create another project in Movie Maker just for his friends on the Cross Country team.

The students do not. however, explicitly express the sense of personal investment that made the instructors anxious when assessing the projects. At no point do they mention being offended by revisions they were expected to make nor do they appear to take evaluation comments personally. Interestingly. they seemed to want to make the essays more personal because they thought their messages would be received better, but the focus remains on the audience rather than themselves.

\section{Students were able to explicitly transfer some concepts from multimodal to print.}

Like their instructors who were able to talk about images replacing text and vice versa. the students were able to express their processes of replacing one medium for another or compositions with only a couple of layers. In fact. Beth was very articulate about how she was able to replace the pictures with text as she moved from the multimodal to the print texts. She explained. 
Well I used a lot of analogies. What lacked in my print essay was I didn't have the pictures to show and explain how the literacies have evolvedhow they are technically classified through scholarly support as literacies. I brought in some interesting analogies to bring some sort of internal picture to their minds. When I say a farmer. they see a guy in overalls working in the field. When I say a chemist. they see a guy in a white lab coat working with bottles with stuff in them. I described a farmer as a chemist. a botanist. and meteorologist try to instill in the reader a picture. I was trying to make them correlate between the two internal ideas-make it interesting and give them a new perspective on what was going on.

Yet while Beth was able to make such a clear articulation about how she replaced pictures with text. for the other four students. the move from the multimodal text they created in project one to the print text of the same topic in project two was more about moving from being concise within the text and allowing the pictures to convey the message to being wordy enough to meet the assignment's page requirement. They offered no other evidence about their processes for moving the same idea from one medium to the other.

\section{Students see multimodal composition as an effective teaching tool more than something they would use later.}

Near the end of the interview. Sarah said that multimodal composition could be used more often in college courses in the humanities and English to "improve critical thinking skills in students. Because you really do stop and think why you are using the different modes and how you are going to use the modes to express something specific to the audience." Will. who is majoring in biology agreed that multimodal would be useful 
for students majoring in English or the humanities and also added education and business majors to the list. However he and the other three students interviewed thought multimodal composition was more valuable as a teaching tool because "pictures enhance our understanding ... if you learn how to incorporate pictures and coordinate the text with your thesis. I think multimodal could help students to understand -for example, an experiment in science - a multimodal presentation [by the professor] could help the students understand the results of a scientific experiment." Pam agreed that multimodal composition could be effective for teaching college classes. She said, "I was thinking about it for psychology because there is a lot of research and making arguments on what scientists and researchers say... So having a digital argument showing [students] the most respected points of view would be a really cool way to learn." Pam also saw the potential for multimodal composition in her future teaching career: "Being a teacher, I can 't just lecture to elementary school kids. I will have to keep their attention. I won't necessarily be creating a digital argument, but composing multimodally in [first year composition] gives me the tools to someday keep my elementary students focused on what I am talking about." Only Sarah mentioned using multimodal projects for improving critical thinking skills in "courses to do with the humanities and English." The other students did see it as an effective method for teaching but appeared unable to imagine how they would use it in their course work.

\section{Technology is an obstacle to students rather than something they are already using on a daily basis.}

One assumption that has generally been made and that has become the basis for incorporating multimodal composition into the classroom is that students are already using the technology for everyday tasks outside the classroom. Thus we should 
incorporate it in the classroom to make students more critical consumers of the technology. However. during the course of these interviews. only two of the students said they felt comfortable with the technology. The other three all spoke of the learning curve involved in the technology often used in multimodal compositions. Pam said, "I had never done a digital argument before until this class. The whole idea of the technology was new to me." Will was also a technological novice and explained. "I have never done anything like that before. I had to learn the technology and how to use a computer to put photographs in with the text." He even went on to say, "I felt dumb with the new technology a lot." Sarah. whose multimodal text was a paper-based travelogue, thought that composing multimodally was easier than writing a paper, but explains, "I knew I was going to stay away from technology. not audio or video types of things. . . I'm really just not good working with those materials." Even Beth. who decided that the paper was a more challenging text to create. said that "if you had asked me in the beginning. I would have probably said the multimodal text was more challenging because it was difficult for me to arrange at first. I wasn't sure exactly what was expected of me . .. I was really confused about exactly what combination of pictures and words to use and how much of each would be acceptable." So even though the technology was not a problem for Beth, understanding the expectations in this new mode did cause some confusion.

\section{Conclusion}

The results of this study seem to indicate that multimodal compositions can be a good place for students to focus on how their arguments relate to their audience. Audience has long been a difficult concept for students to grasp in first-year composition. 
Paul Sladky (1994) explains how this issue of audience is difficult to transfer from the context of the outside world into the classroom:
Although the idea that writers engage in negotiated transaction with readers is theoretically. and even practically, alive in the universe of discourse outside the composition classroom. inside it. our students know in their bones that genuine. negotiated transaction with readers is, for the most part, purely fiction. (p. 4)

Technology has been offered as a cure to the problem of audience (Cohen \& Riel, 1985; Albers, 2003; Thatcher. 2005: Hunt \& Hunt, 2006; Lindroth, 2007: Willerton. 2007). But even technology is often not enough. In his 2002 article "Digital spins: The pedagogy and politics of student-centered e-zines." Jonathan Alexander describes the frustration instructors have getting students to write for a broad audience when realistically only the instructor will be reading their work. Even when publishing student work, "there comes a point when students realize that both booklets and web sites reach a very limited audience" (p. 388). However, multimodal compositions seem to offer another option for getting students to reach out to a broader audience.

Issues of audience were pervasive in the student interviews. and four of the five students thought that the number one criteria for assessing multimodal compositions should be "having a clear message that reaches the audience." It is not clear why the concept of audience is expanded for students in multimodal composition. Possibly, it is due to the novelty of new media composition and as the newness wanes. so may the enthusiasm for audience. The students" desire to connect with their audience in multimodal composition and how to transfer that enthusiasm about the audience to their 
print texts is certainly an area open for more research. In the meantime, beginning the first year composition course with a multimodal assignment may be one way to help students focus on a broader audience than just their instructor.

Even though the students were focused on audience, the students need more than just their intuition to guide them in making presentation decisions. Like their instructors, students need a rhetorical vocabulary to discuss presentation issues in their multimodal compositions. Scholars in the field seem to agree that because students are consumers of multimodal texts. they know a great deal about those texts (Keller, 2007; Takayoshi \& Selfe, 2007: Reid. 2008) However. what exactly the students "know" about the multimodal texts they consurne has not been thoroughly investigated. This study suggests that allowing students to rely on their intuition about issues of presentation can cause a variety of problems. Within the multimodal projects. there needs to be less reliance on creativity and intuition and more focus on creating projects with a balance of ethos. pathos. and logos. One place to begin is with class time spent on how to read visual rhetoric and transfer those concepts to their own compositions. Students need to be able to decipher the rhetorical elements of the multimodal arguments in the same way that they often learn to decipher the rhetorical elements of a print text. This rhetorical focus may help students to compose more sophisticated projects.

The focus on audience made the students want to be concise in their multimodal arguments. All of the students interviewed understood their instructors messages about the need to keep the projects focused and concise in order to keep the audiences' attention. These same studerts all admitted to finding ways to be "wordy" for the sole purpose of increasing page length in written texts. However. Beth found that she could 
keep the message of her print text project focused by using analogies to replace the work done by the pictures in her multimodal project. Beth offers us a way to transfer a specific rhetorical device in multimodal composition back to print composition. Instructors should consider using this example as a starting place to experiment with ways to transfer the focus students have on keeping the audiences ${ }^{*}$ attention in the multimodal composition to the print texts. This approach may help students feel like they have alternatives to what Will described as "rambling about nothing and if you make your rambling smart enough. the teacher likes it."

More research into students ${ }^{\wedge}$ relationship with multimodal composition and technology. Earlier claims that students are familiar with the technology and therefore, feel comfortable using it may be overstated. For example. in a forthcoming article by Alexander. Powell. and Borton. 39\% of students reported that what they liked least about composing multimodal essays were the technical details such as the limited resources and having to learn and use new technologies. In addition. $23 \%$ found composing multimodally tedious and a lot work to use these technologies in addition to crafting an argument. Thus, students may not always be as in touch with the new technologies and as prepared to use them as their instructors assume that they are. 


\section{CHAPTER 5 \\ CONCLUSION}

This study examines the similarities and differences in the ways instructors and students talk about print and multimodal compositions and if the vocabulary they use to talk about each transfers or if they need a new vocabulary to discuss the multimodal compositions. The results of this study seem to indicate that language common to both print and multimodal composition. such as having a clear assertion. was transferrable both between the print and multimodal projects and between the instructors and their students. The instructors interviewed for this study were able to use the terms in the same way for print and multimodal composition when instructing their students on the new media, and the students interviewed were able to understand the concepts-a fact made apparent by their comments about creating clear assertions in both projects.

This study also indicates that multimodal composition seems to be a good place to focus on composing for a broad audience. Unlike the print text where students had trouble seeing an audience other than the instructor. all of the students interviewed were very clear about the ways their assertions or their presentation choices in the multimodal compositions would affect their audience. Audience was foregrounded by the students to the point that occasionally they even chose to ignore requirements of the assignment. such as using sources from their required reading. because they thought these elements 
would not be effective in keeping their audience focused on the message of the composition.

However, this focus on audience did not transfer back to the print text. Instead, the students saw their print text audience as their teacher. The focus on audience allowed students to understand the need to keep the information very concise in their multimodal projects. They knew that if they included too much information, they would "have been swamping the thing and the audience would have lost interest." This is the opposite of how they felt about their print text projects where the goal was most often to be "wordy" in order to meet the page requirement rather than considering how their audience might read the paper or what they might take from its message.

Transfer of concepts was an even bigger concern with issues of presentation because the instructors who were all new to multimodal composition and their students had no common vocabulary or metalanguage about the presentation and design issues which surround multimodal composition. To describe the presentation of the multimodal projects, the instructors reverted to using terms descriptive of the physical world. Presentations which did not take advantage of the affordances became "flat" or digital arguments with too much text on each screen were "heavy." The students used no such specific language to describe the presentation of the projects but instead had a "more is better" approach which relied on their intuition to guide them in making presentation decisions. This approach resulted in projects with multiple layers of pictures, text, music, and narration but showed a lack of critique of the presentation choices by the students.

The lack of a language to talk about presentation issues combined with the time the instructors perceived that students spent on the multimodal compositions led to 
evaluation anxiety for the instructors. All three instructors expressed anxiety about multimodal evaluation that was not present in their evaluation of the print texts. Allison aptly articulates the problem of evaluation in other mediums: "There is less written text in there to evaluate ... There are other issues you have to consider; the word isn't the only thing communicating or conveying the meaning." While compositionists are trained evaluators of the print text, they are less skilled at evaluating the combinations of video, audio, pictures, and text that multimodal compositions can take on. They also felt conflicted about the amount of time and personal investment they perceived the students had in their projects. Thus the instructors often felt ill-equipped to evaluate the multimodal compositions.

The discussion of evidence in this study is challenging to interpret. While the students discussed evidence more in the print projects than in the multimodal projects, the results were complicated by the fact that the instructors expected more secondary source evidence in the second project regardless of whether it was print or multimodal. However because two of the instructors assigned the multimodal composition first and only one instructor assigned it second, the results were conflated to appear that the multimodal compositions required less secondary source material.

The idea that students today are already immersed in the technology used to create multimodal compositions is also complicated by the results of this study. Three of the five students felt very uncomfortable with the technology used to compose multimodally, and Will estimated that it took him thirty-five hours to learn the technology involved in creating his digital composition. Another interesting result was that even if the students were comfortable with the technology, they were not comfortable 
comprehending the expectations of their instructor for a multimodal composition. Thus even though some students may be comfortable enough with the technology to create digital projects for YouTube or MySpace, they do not necessarily transfer their criteria for those projects to more academic projects.

While the attitudes of the students interviewed in this study support past research about student enthusiasm in multimodal composition (Hull, 2003; Hawisher \& Selfe with Moraski \& Pearson, 2004; Selfe, 2004; Hull \& Nelson, 2005; Hull \& Katz, 2006), their enthusiasm was complicated by the fact that they did not necessarily see multimodal composition as something they would use in other classes. While almost all of the students saw multimodal as a useful tool for instructors lecturing in humanities and social science classes, they could not imagine assignments where they would use multimodal composition in these classes nor could they imagine their professors in these classes allowing them to turn in assignments composed multimodally.

Student enthusiasm may also have been high because this was a self-selected group - all the students who volunteered to be a part of the study were selected. These students were probably more enthusiastic about the multimodal projects than those who did not volunteer to be part of the study. Moveover, novelty may contribute to enthusiasm. Once the newness of composing in new media wears off and the students become more familiar with multimodal composition, their enthusiasm may wane.

Another limitation of the study was the focus on only novice instructors. While it was important to capture the ways novice instructors discussed their challenges with teaching and evaluating the multimodal compositions, it will also be beneficial for future research to examine how experienced instructors of multimodal composition deal with 
presentation issues and if they experience similar evaluation anxiety. It will also be important to see how experienced instructors manage issues of knowledge transfer between multimodal and print texts. How do they help the students establish context connections as they compose in various mediums?

Finally, the fact that Allison and Michelle used different assignments than Rachel made the results of the study a bit more difficult to compare at times. Allison and Michelle's decision to allow the students to choose their mediums also made their job of evaluating the various modes more challenging for them than Rachel who required each student to create a digital argument. However, the positive side of the different assignments was that it allowed a different perspective on the composing process.

\section{Implications of the study}

This study both suggests that it is possible to transfer from the rhetorical vocabulary compositionists use to discuss print to multimodal compositions and that we need to work harder to increase these points of transfer. The issue of knowledge transfer from multimodal to print composition and vice versa is the main issue on which we should capitalize as composition researchers. While the students interviewed in this study may not be able to see ways to incorporate multimodal compositions into their other post-secondary classes, most of them will probably be asked to compose some type of multimodal project in their future jobs if not in their classes. They will probably be asked to compose various print texts as well. If we can learn the elements best taught by the various mediums, we can begin to look at how those elements can be transferred between the composing mediums. 
More training is needed in areas of visual rhetoric and design for instructors planning to teach multimodal composition so that instructors will have a vocabulary with which they can be comfortable discussing presentation issues. Such training may increase instructor's confidence in teaching their students how to analyze multimodal compositions and compose multimodal projects in first-year composition. Kress and others have proven that image is overtaking the printed word in professional communication, yet many programs have just recently started including classes in visual rhetoric and design. Thus instructors currently teaching multimodal composition often rely on their own reading to teach themselves about new media and multimodal composition.

In order for transfer between multimodal composition and print texts to take place, a new way to look at the rhetorical vocabulary which would include focus on the visual and print rhetorical elements of the compositions would need to be developed. This would allow for a common vocabulary between students and their instructors as well as minimizing the need to rely on intuition as a guide in the presentation process. While design grammars have been outlined by the New London Group (1996), Manovich (2001), and others, a multimodal grammar that combines and expands rhetorical concepts with design concepts - a vocabulary that meets in the middle, as Ball suggests, might be most useful for the transfer of students' knowledge about print text composing to their knowledge of multimodal composing and vice versa.

Instructor training in this vocabulary along with a stronger focus on visual rhetoric might also help to alleviate some of the instructors' anxiety about evaluating the multimodal projects. This enhanced grammar could be used to develop rubrics which 
would include the elements which are transferable from print text project to multimodal projects, but it could also deal with the presentation issues that often left instructors with no way to talk about their students" projects other than to describe them as "cool" or "interesting" or "creative."

\section{Areas for further research}

The question becomes how would this enhanced grammar be developed and what would it look like? This question would need to be answered in future research. Some directions for new research would include finding a way to think about cinematic and design terms rhetorically. For example, in the piece from Daniel Keller's "Thinking Rhetorically" discussed in Chapter 1, how could the transitional terms Keller uses like fade in, fade out, and soundmark be given more of a rhetorical focus or even a language studies focus? Could we talk about these issues through the lens of coherence-a term already common for print compositions with most instructors--rather than just in terms of the design language?

Discussions of issues such as arrangement and organization were practically nonexistent in the student and instructor interviews. Michelle briefly mentions storyboarding as a way to teach organization in the multimodal composition but does not elaborate on it or use it in her print texts. Would there be a way to use this technique of organizing the layers in the multimodal compositions to teach students how to layer their print texts? The digital argument "Tanning Beds" used the multiple layers of layers of music, narration, pictures, and text to argue the dangers of tanning bed use. Though the layers were not always as rhetorically effective as they might have been, would a discussion of the particular work done by each of the layers and how that layer might be organized 
within a print text have helped students see a way to develop their print text arguments without having to resort to simply "being wordy"? Could a specific discussion on the pathos and ethos created by a musical selection in the multimodal composition transfer to a similar way to argue in print? Could the ethos created by an expert source in the print text be transferred into a layer of the multimodal composition? Beth discusses her use of analogy to replace the pictures she used in the multimodal composition. Could discussions of analogy and metaphor be developed as a way of transferring the spatial issues of multimodality to print?

Focusing on assignments with specific audiences might also help transfer the concept of audience from the multimodal compositions to print compositions. For example, instructors could create assignments much like Michelle and Allison's which ask students to compose a multimodal project and a print text project on the exact same topic. As each assignment is being drafted, instructors could focus on how the argument is developing in terms of audience. What does this series of pictures say to the audience? How can an analogy be developed that will create a similar layer, and thus a similar effect on the audience, in the print text argument? This type of assignment would help make obvious what works best in print and what is best accomplished in a different medium. Likewise, in order to foreground the issue of audience, students could be asked to compose two multimodal texts on the same topic but for two different audiences-a traditional academic audience and a more general audience. This may help compositionists better understand the trouble students have with issues of audience in print text compositions.

\section{Conclusion}


Kress was correct in 1999 when he stated that Composition's current theories of language would be inadequate for the composition tasks that lay ahead. And while Kress, as part of the New London Group, and others sought to bridge the gap between texts which just consisted of the printed word on the page and multimodal and new media texts, the design grammars they suggest may actually push multimodal projects further away from the expertise of compositionists. While it is true that instructors do need a design vocabulary to discuss the presentation issues of multimodal composing, they also need to be able to draw on their strengths as compositionists. And the students need to be able to make connections between composing multimodally and composing print texts. In order for these connections to be made, instructors must transfer some of the print text language to their teaching of multimodal compositions. They must find the "middle ground" Cheryl Ball discusses between design and composition. A focus on rhetorical terms in both types of composing will only work to strengthen the students' knowledge of the vocabulary and make them feel more comfortable using it regardless of their composing medium.

Ultimately, what may need to happen in order for new media to find its place uncontested in English programs is to move away from a focus on multimodal composition as a new literacy and toward a focus of the rhetorical aspects of multimodal composition. Rather than seeing it as something new and different, which would call for a new and different way of talking about it, the focus needs to be where scholars such as Ball, Wysocki, Yancey, and others have called for it to be-multimodal composition as an extension of writing which grounds itself in the rhetorical aspects of writing compositionists focus on everyday in their pedagogy and their research. This move 
would seem to end some of the questions about whether or not multimodal composition belongs in English because rhetorical analysis of texts has long been the focus of compositionists. It might also help instructors feel less anxious about teaching multimodal composition for the first time. 


\section{REFERENCES}

Ackerman, J. (1991). Reading, writing, and knowing: The role of disciplinary knowledge in comprehension and composing. Research in the Teaching of English, 25 (2), $133-178$.

Alexander, J. (2002). Digitals spins: The pedagogy and politics of student-centered ezines. Computers and Composition, 19,387-410.

Anderson, D. (2008). The low bridge to high benefits: Entry-level multimedia, literacies, and motivation. Computers and Composition, 25, 40-60.

Ankerson, I., Sapnar, M., (2000). While Chopping Red Peppers, Poems That Go, URL (accessed 17 March 2008):

http:/www poemsthatgo.com/gallerv/spring2000 redpeppers/start.hm

Ball, C. (2006). Designerly $\neq$ Readerly. Convergence: The international journal of research into new media technologies, 12 (4), 393-412.

Beaufort, A. (1998). Transferring writing knowledge to the workplace: Are we on track? In M. Garay and S. Bernhardt (Eds.), English Teaching and the New Workplace (pp. 179-199).

Bezemer, J., Kress, G. (2008). Writing in multimodal texts: A social semiotic account of designs for learning. Written Communication, 25 (2), 166-195.

Bolter, J.D., Grusin, R. (2000). Remediation: Understanding new media. Cambridge, MA: The MIT Press.

Borton, S. (2005, Spring). Self analysis: A call for multimodality in personal narrative composition. Computers and Composition Online: An International Journal.

Borton, S., Huot, B. (2007). Responding and assessing. In C. Selfe (Ed.), Multimodal composition: Resources for teachers (pp. 99-111). Cresskill, NJ: Hampton Press.

Callow, J. (2006). Images, politics, and multiliteracies: Using a visual metalanguage. Australian Journal of Language \& Literacy, 29 (1), 7-23.

Cooper, M. (2005). Bringing forth worlds. Computers and Composition, 22, 31-38. 
Crowley, S. (1998). Composition in the university: Historical and polemical essays. Pittsburgh: U of Pittsburgh Press.

Daley, E. (2003). Expanding the concept of literacy. Educause Review, 38 (2), 32-40.

Doheny-Farina, S. (1989). A case study of one adult writing in academic and nonacademic discourse communities. In C. Matalene (Ed.), Worlds of Writing: Teaching and Learning in Discourse Communities of Work (pp. 17-42). New York: Random House.

Flower, L., \& Hayes, J. (1981). The pregnant pause: An inquiry into the nature of planning. Research in the Teaching of English, 15, 229-243.

Fehring, H. (2005). Critical, analytical, and reflective literacy assessment: Reconstructing practice. Australian Journal of Language \& Literacy, 28(2), 95-113.

Ford, J. (2004). Knowledge transfer across disciplines: Tracking rhetorical strategies from a technical communication classroom to an engineering classroom. IEEE Transactions on Professional Communication 47 (4), 301-315.

Geisler, C. (1994). Academic literacy and the nature of expertise: Reading, writing, and knowing in academic philosophy. Hillsdale, NJ: Lawrence Earlbaum Associates.

George, D. (2002, September). From analysis to design: Visual communication in the teaching of writing. CCC 54 (1), 11-39.

Haas, C. (1994). Learning to read biology: One student's rhetorical development in college. Written Communication 11 (2), 43-84.

Hamston, J. (2006). Pathways to literacies: Student teachers' critical reflections on a multimodal text. Australian Journal of Language \& Literacy, 29 (1), 38-51.

Hawisher, G., Selfe, C. (1999). Introduction: The passions that mark us: Teaching, texts and technologies. In G. Hawisher \& C. Selfe. Passions, pedagogies, and $21 \mathrm{st}$ century technologies (pp. 1-12). Logan, UT: Utah State University Press.

Hawisher, G., Selfe, C., Moranski, B. \& Pearson, M. (2004) Becoming literate in the information age: Cultural ecologies and the literacies of technology. $C C C 55(4)$, 642-692.

Herrington, A. (1985). Writing in academic settings: A study of the contexts for writing in two college chemical engineering courses. Research in the Teaching of English $19(4), 331-359$. 
Hill, C. (2004). Reading the visual in college writing classes. In C. Handa (Ed.), Visual rhetoric in a digital world: A critical sourcebook (pp. 107-130). Boston: Bedford/St. Martin's.

Hobbs, C. (2004). Learning from the past: Verbal and visual literacy in early modern rhetoric and writing pedagogy. In C. Handa (Ed.), Visual rhetoric in a digital world: A critical sourcebook (pp. 55-70). Boston: Bedford/St. Martin's.

Hull, G.A. (2003) Youth culture and digital media: New literacies for new times. Research in the teaching of English 38(2), 229-233.

Hull, G.A., Nelson, M.E. (2005) Locating the semiotic power of multimodality. Written Communication 22(2), 224-261.

Hull, G.A., Katz, M. (2006) Crafting an agentive self: Case studies of digital storytelling. Research in the teaching of English 4I(1), 43-81.

Jewitt, C. (2005, September). Multimodality, "reading," and "writing" for the 21st century. Discourse: Studies in the Cultural Politics of Education 26, (3), 315331.

Keller, D. (2007). Thinking rhetorically. In C. Selfe (Ed.), Multimodal composition: Resources for teachers (pp. 49-63). Creskill, NJ: Hampton Press.

Kenner, C. (2004). Becoming biliterate: Young children learning different writing systems. Stoke on Trent: Trentham Books.

Kostelnick, C., Hassett, M. (2003) Shaping information: The rhetoric of visual convention. Carbondale, IL: Southern Illinois University Press.

Kress, G. (1999). "English" at the crossroads: Rethinking curricula of communication in the context of the turn to the visual. In. G. Hawitheyr \& C. Selfe (Eds.) Passions, pedagogies and 21st century technologies (pp. 66-88). Logan, UT: National Council of Teachers of English.

Kress, G. (2003). Literacy in the new media age. London and New York: Routledge.

Kress, G., van Leeuwen, T. (2001). Multimodal discourse: The modes and media of contemporary communication. New York: Oxford University Press.

Kryder, L. (1999). Mentors, models, and clients: Using the professional engineering community to identify and teach engineering genres. IEEE Transactions on Professional Communication 42 (1), 3-11. 
Lauder, W., Reynolds, W., and Angus, N. (1999). Transfer of knowledge and skills: Some implications for nursing and nurse education. Nurse Education Today 19, 480-487.

Lea, M. (1998). Academic literacies and learning in higher education: Constructing knowledge through texts and experience. Studies in the Education of Adults (30), 156-171.

Lea, M., Street, B. (1998). Student writing in higher education: an academic literacies approach. Studies in Higher Education 23 (2), 157-172.

Lin, C. (2007). Organizational website design as a rhetorical situation. IEEE Transactions on Professional Communication 50 (1). 35-44.

McCarthy, L. (1987). A stranger in strange lands: A college student writing across the curriculum. Research in the teaching of English 21 (3), 233-265.

Manovich, L. (2001). The language of new media. Cambridge, MA: The MIT Press.

Metros, S.E., Woolsey, K. (2006). Visual literacy: An institutional imperative. Educause Review, 41 (3), 80-81.

Mila, C., Sanmarti, N. (1999). A model for fostering the transfer of learning in environmental education. Environmental Education Research 5 (3), 236-266.

Moran, C., Herrington, A. (2003). Evaluating academic hypertexts. In P. Takayoshi \& B. Huot(Eds.), Teaching writing with computers: An introduction, (pp. 247-257). Boston; Houghton Mifflin.

New London Group. (1996). A pedagogy of multiliteracies: Designing social futures. Harvard Educational Review, 66 (1), 60-92.

Powell, B. (2007). Literacy and Public Transportation. In C. Selfe (Ed.), Multimodal composition: Resources for teachers Creskill, NJ: Hampton Press.

Selfe, C. (1999). Literacy and technology: A story about the perils of not paying attention. CCC, $50(3), 411-436$.

Selfe, C. (1999). Technology and literacy in the twenty-first century: the importance of paying attention. Carbondale: Southern Illinois University Press.

Selfe, C. (2004). Towards new media texts: Taking up the challenges of visual literacy. Writing new media: Theory and applications for expanding the teaching of composition (pp. 67-110). Logan: Utah State University Press. 
Shipka, J. (2005). A multimodal task-based framework for composing. CCC, 57 (3), 277306.

Stein, P. (2004). Representation, rights and resources: Multimodal pedagogies in the language and literacy classroom. In B. Norton \& K. Toohey (Eds.), Critical pedagogies and language learning, (pp. 95-115). Cambridge: Cambridge University Press.

Takayoshi, P. (1996). The shape of electronic writing: Evaluating and assessing computer-assisted writing processes and products. Computers and Composition, $13,245-258$.

Takayoshi, P., Selfe, C. (2007). Thinking about multimodality. In C. Selfe. Multimodal composition: Resources for teachers (pp. 1-12). Cresskill, NJ: Hampton Press.

Vincent, J. (2006). Children writing: Multimodality and assessment in the writing classroom. Literacy $40(1), 51-57$.

Westbrook, S. (2006). Visual rhetoric in a culture of fear: Impediments to multimedia production. College English, 68 (5), 457-478.

Wysocki, A. (2004). The sticky embrace of beauty: On some formal relations in teaching about the visual aspect of texts. Writing new media: Theory and applications for expanding the teaching of composition (pp. 147-97). Logan: Utah State University Press.

Yancey, K. B. (2004). Made not only in words: Composition in a new key. CCC, 56 (2), 297-328. 


\author{
APPENDIX A \\ English 105 \\ Intermediate College Writing \\ Project 1: Multimodal Profile Essay
}

\title{
Brief Description
}

For this assignment you will compose a multimodal profile essay describing and commenting on one individual's experiences with literacy.

\section{Expanded Description}

For our purposes, a multimodal essay is one that combines two or more mediums of composing, such as audio, video, photography, printed text, magazine cut-outs, a hypertext web document, a website, a poster board, video game, etc. One of the goals of this assignment is to allow you to explore different modes of composing.

We're taking literacy as our focus this semester, considering what constitutes literacy, how one becomes literate, how our notions of literacy change over time and with the introduction of new technologies, etc. In this multimodal profile, you should focus on the individual's experiences as a literate person. (You may also choose to focus on one particular literacy event in the person's life.) Ideally, the interpretations you present in your multimodal essay will be informed by assigned readings and class discussions.

This assignment requires field research, meaning that you will have to go out and research your subject, much like a reporter on an assignment. You will observe, interview, and take notes on your subject, and then compile this information you gather to form a multimodal essay that both informs and engages readers. The person you profile should be someone you have access to on a semi-regular basis since you will be visiting/seeing/interviewing your subject several times. Regardless of who you choose to profile, you will need to incorporate observation and interviews into your multimodal essay.

\section{Requirements}

Your multimodal essay should:

- Employ the affordances (capabilities) of the medium you're using in effective rhetorical ways.

- Be characterized by careful design that helps to convey meaning.

- Add information value to our discussion of literacy issues/themes.

- Be instructive, that is, inventive, creative, insightful. 
- Do more than simply inform the audience; it should also help readers/viewers reflect on and gain insight into the subject.

- Cite any source you use, whether an image, an interview, a magazine ad, or an audio, video, TV clip.

I'm not setting a required length for this project. As you decide on an appropriate length, you need to consider rhetorical elements (audience, purpose, situation, genre, context) that will affect the outcome of your project, and then choose a length that works for those purposes and reasons. If you have questions about whether or not your project is

sufficient lengthwise, ask me and we can work something out together. Remember, you'll be handing this project in to me, so make sure it's in a format I can access easily.

\section{Criteria for Evaluation}

For this assignment, Satisfactory projects will:

- Include only those details relevant to a discussion of the person's experiences as a literate person

- Effectively incorporate and cite field research (observation and interview), synthesizing information rather than presenting a straight reporting of facts

- Reveal the writer's attitude toward the subject, offering an interpretation of it

- Effectively employ the affordances the selected mediums offer

- Contain evidence of careful planning and an attempt to present information vividly

Unsatisfactory projects will fall short of these minimum requirements; Excellent projects will exceed them.

\section{Project 1 Syllabus}

(Subject to Change)

Reading and writing assignments are due on the days listed.

All readings are found in the Classpaks unless otherwise listed.

T $\begin{aligned} & \text { Introduction to course and each other. Skills and talents survey } \\ & \text { R } 1 / 11 \quad \text { Read: Project } 1 \text { assignment sheet; Barton and Hamilton chapter } \\ & \text { Parts I \& II of the DeRosa article }\end{aligned}$
Bring: questions about Project 1 , ideas for person to profile, and
notes/reactions to Barton and Hamilton and DeRosa
Credit)
The last day to add is also the last day to delete a
course from your record. After that date, a grade of
"W" is assigned for all withdrawals for S 2007.
Monday, Jan. 15. Dr. Martin Luther King Jr. Holiday


Read: Shipka article

Bring: notated Shipka article

In Class: Looking at examples of cool multimodal compositions

$\mathrm{R} \quad 1 / 18$

section)

literacy sponsors-

from sponsoring this person's
Read: Brandt, pages 7-15 (to end of "Sponsorship and Access"

Bring: Notes on Brandt; thoughts on your subject's who are they? What did they stand to gain literacy development?

$\mathrm{T} \quad 1 / 23$

Read: Brandt (to end) and Baca

Post: Your reader's response to pbwiki

R $\quad 1 / 25$

Citing weird sources and Subject and Design preview: Come prepared to bring ideas about the share what you've learned about your subject and ideas, and get reactions from modes you'd like to use to present your classmates.

Friday, Jan. 26. Last day to apply for degree

Monday, Jan. 29. Last day to withdraw with $50 \%$ tuition credit

T $\quad 1 / 30 \quad$ Peer Review

R 2/1 Project 1 Due

Read: Baca and Rodriguez essays

Post: Reader's response to pbwiki 


\section{APPENDIX B \\ Spring 2007/English 102 \\ Digital/Visual Argument Project}

For this project you will design a digital argument on a topic generated through our class discussion. Because it is important that you learn to effectively collaborate, you will complete this project as a member of a group. Your group will be responsible for investigating a topic, developing a problem of appropriate scope, providing a solution of the appropriate scope, and presenting appropriate evidence for your proposal. You will use your own experiences and knowledge, primary sources, and internet sources (analyzing them for validity using the guidelines we discussed in class for this project). We will work together to learn about the different computer programs and equipment necessary for completing the assignment. The group work portion of this project will be done during our meeting time.

This project will help you do the following:

- Develop a proposal argument that clearly indicates a problem to be solved.

- Establish the importance (or salience) of the problem using clear and convincing evidence.

- Clearly indicate cause(s) for the problem or circumstances surrounding the issue using clear and convincing evidence.

- Provide appropriate contextual information for the viewer to understand both the problem and its causes.

- Clearly indicate a solution and/or call for action.

- Use convincing evidence to convince the reader that the proposed solution(s) will work towards correcting the problem.

- Integrate images, text, graphics, and audio to present an effective argument.

- Utilize the three types of argument (ethos, pathos, and logos)

- Become comfortable with utilizing equipment (microphones, scanners, digital cameras), computer software programs (moviemaker, photoshop, flickr., etc.), and graphic organizers (storyboards and team responsibility sheets).

This project will work toward several issues. First, it will involve in you in identifying effective strategies composers use in their arguments to establish visual impact, coherence, salience, and organization and introduce you to some vocabulary (e.g. visual impact, coherence, salience, affordances, etc.) to help you in understanding and using visual rhetoric. Second, it will help you to develop proposal arguments: identifying a problem, investigating it, and providing a reasonable and possible solution. Third, it will help you to collaborate effectively with other composers on a mutual project. 


\section{Tentative Schedule:}

Feb. $6^{\text {th }}$ Group time for searching internet sources and developing a clear proposal and solution.

Feb. $8^{\text {th }}$ Movie maker tutorial and produce short movie; finish proposal and solution and develop task list

Feb. 13 Begin storyboard and scanning images: group meetings with me.

Feb. 15 Scanning images and working on storyboard: group meetings

Feb. 20 Peer review of story board and composing digital argument on movie maker

Feb. 22 Work time

Feb. 27 Work time and complete digital argument

\section{Group work guidelines}

Every group needs to select someone responsible for designing a task list and keeping track of what is being completed and when. Each group also needs to designate a facilitator, someone who can keep the group on task and keep the conversation productive and focused. Someone also needs to be the writer-someone who actually sits at the keyboard. The last member of the group needs to be the one to be responsible for the technology, seeking answers to problems the group may be developing. Although each person has a main responsibility, each person is responsible for the success of the group. Also, please remember that the person at the keyboard and the tech person does not necessarily have to be a male $(-)$ All communicating between group members will be through group pages on Blackboard. A portion of your grade will depend upon your contribution to the work of the group. When it comes to collecting images and composing the dialogue, you need to divide the project into four or so equal parts, so that each person will be responsible for part of the collecting of images and writing. You will have time in class to work together to make the four parts work together.

\section{What you will be responsible for including with your finished product:}

1. A complete list of the sources your group utilized

2. A complete storyboard

3. A complete script

4. Your finished digital argument- saved either on $\mathrm{CD}$ or on a detachable E-drive

5. A one-page reflective piece per student re: the digital argument project

6. An evaluation form that rates the participation and effectiveness of the members of your group

\section{Some hints for your project:}

* Resist the temptation to begin using movie maker until you have all your images in a jpeg format and in the form you want to use, a complete script, and a complete storyboard.

* I would also recommend a couple of run-through sessions where you recite your dialogue. Narration that seems right on paper often doesn't sound the same when you recite it aloud.

* Check that your images and your dialogue work well together. I found out some of the images I wanted to use really didn't make sense when I added the dialogue. 
- Put your transitions and effects in before you do your narration. The addition of effects and transitions does affect the speed of your digital argument and can throw your narration to images ratio off.

- Do your narration last!

* You do not have to use music, but if you chose to, please make sure you follow the directions in the tutorial. The addition of music comes lastyou must finalize your digital argument into a media file before you can add your music.

- The advice about saving everything in one folder is not just a suggestion. Your moviemaker program actually pulls from that file every time you use the program.

* Pay attention to the volume when you do your narration so that you have the room to both lower and increase the volume when you have a real viewer.

I hope that this is not only a challenging project but also one that you enjoy. Use your creativity and let me know what kind of questions you have. 


\section{APPENDIX C}

Interview questions for instructors teaching multimodal arguments

1. Describe the assignment you just finished grading.

2. What went particularly well with the assignment?

3. What problems did you encounter with the assignment?

4. How did you assess the assignment?

5. Choose a project that earned a "B". Tell me about why it earned a B. What was good and what was bad about the project?

6. Choose a project that you felt was particularly good. Tell about why it is such a good project.

7. Choose a project that you felt was particularly bad. Tell about what made it a bad project.

8. What do you look for when you are assessing a multimodal project/ print project?

9. What challenges did you have assessing the multimodal project/ print project? (If they use a rubric, ask to see it -ask questions about the rubric.)

10. How did assessing the multimodal assignment/ print project differ from assessing the print/ multimodal assignment?

11. Which is more difficult to assess the multimodal or print? Why?

12. Any other questions or comments? 


\section{CURRICULUM VITAE}

Sonya C. Borton

Home

109 Summit Ave

Fort Washington, PA 19034

(502) 931-2803

bortons aphilauedu

Office
Philadelphia University
School of Liberal Arts
School House Ln. \& Henry Ave.
Philadelphia, PA 19144

(215) $951-2600$

\section{Education}

August, 2008

August, 1994

May, 1992
Ph.D. in Rhetoric and Composition, University of Louisville, Louisville, $\mathrm{KY}$

Master of Arts in English literature, Murray State University, Murray, KY

Bachelor of Arts in English and History, Bellarmine College, Louisville, KY

Graduated with Distinction

\section{Dissertation}

Multimodal and Print Composition: An Examination of Instructors and Students Transferring Rhetorical Knowledge in First-Year Composition

Committee: Joanna Wolfe (Chair), Debra Journet, Annette Powell, Thomas Byers, Cynthia Selfe

\section{Publications}

"Thoughts on Responding to and Assessing Multimodal Texts." with Brian Huot. Multimodal Composition for the $21^{\text {st }}$ Century: A Resource Book for Teachers. Ed. Cynthia L. Selfe. Creskill, NJ: Hampton Press. September 2007.

"Self Analysis: A Call for Multimodality in Personal Narrative Composition." Computers and Composition Online: An International Journal. Spring 2005. http/ whw basu.edu/cconline borton borton.htm

\section{Conference Presentations}

"How Rhetorical Elements Differ in Student Print Texts and Multimodal Compositions." 
Conference on College Composition and Communication. New Orleans, LA. 4 April 2008.

"Online Mentoring and the Use of a Wiki in an English Graduate Program." The $20^{\text {th }}$ Penn State Conference on Rhetoric and Composition. State College, PA 10 July 2007.

"The ABCs of Program Assessment: One Writing Program's Attempt to Develop More Complete Teachers." National Council of Teachers of English. Nashville, TN. 17 November 2006.

"Using Narrative to Communicate Tacit Knowledge and Increase Professionalization for Underprivileged Women in Academic Medicine." Thomas R. Watson Conference on Rhetoric and Composition. U of Louisville. Louisville, KY. 6 October 2006.

"Critical Reflection: Workshopping, Revising, and Grading in the Multimodal Classroom." College English Association $37^{\text {th }}$ Annual Conference. San Antonio, TX. 7 April 2006.

"Improving Retention Rates of Women \& Minorities in Medical School through Mentoring." Conference on College Composition and Communication. Chicago, IL. 24 March 2006.

"Charles Chesnutt's Depiction of the Color Line: Bold Boundary, Blurry Middle Ground, or Both?" Midwest Modern Language Association. Milwaukee, WI. 11 November 2005.

"Habitus, Cultural Boundaries, and the Subversive Methods of African American Women in the Nineteenth-Century." Feminisms and Rhetorics Conference. Houghton, MI. 8 October 2005.

"Composing Images, Creating Texts: A Conversation about Incorporating Multimodality into the Composition Classroom." Conference on College Composition and Communication. San Francisco, CA. 19 March 2005.

"The Significance of Think-Alouds on the Revision Process." National Council of Teachers of English. Indianapolis, IN. 19 November 2004

"Incorporating Multimodal Projects into the Classroom: Sharing Audio and Video Projects." (with Cynthia Selfe and Literacy, Technology, and Education class). Thomas R. Watson Conference on Rhetoric and Composition. U of Louisville. Louisville, KY. 7 October 2004.

"Spare Parts: The Female Members of the Frankenstein Family." Pop Culture Association of the South / American Culture Assoc. of the South. New Orleans, LA. 23 September 2004. 
"Professional Development for Graduate Students and Those Who Mentor Them."

Conference on College Composition and Communication. Nashville, TN. 19 March 1994.

"Basic Writing, Basic Success: The Evolution of the Basic Writing Program at Murray

State University." The Wyoming Conference on English. U of Wyoming. Laramie, WY. 22 June 1993.

\section{Professional and Administrative Experience}

April, 2007-

December 2007

January, 2007-

January, 2008

June, 2006-

May, 2007

June, 2005-

Present

June, 2004-

May, 2006

June, 2004-

April, 2005
AP English Language and Composition Course Auditor

The College Board

Read and assess Advanced Placement English Language and Composition syllabi to determine if the courses are following the guidelines set for AP Courses.

General Education Curriculum Committee Assessment Reader University of Louisville

Read and assess sample materials from the General Education Courses at the University of Louisville for critical thinking, cultural diversity, and/or effective communication.

Assistant Director of Composition-Business Writing University of Louisville, Louisville, $K Y$

Liaison to the Business School. Responsible for developing outcomes for the Business Writing course, conducting workshops for Business Writing instructors, teaching Honors Business Writing, and conducting an assessment of the Business Writing course according to guidelines developed by the General Education Committee.

AP English Language Exam Reader

Educational Testing Service

Read and assess the Advanced Placement English Language and Composition Examinations.

Assistant Director of Composition

University of Louisville, Louisville, $K Y$

Mediate problems between students and composition instructors, evaluate student portfolios, plan composition course schedules each semester, organize monthly instructor workshops, and organize assessment of writing program.

Assistant Director of the 2005 International Narrative Conference University of Louisville, Louisville, $K Y$ 
7-9 Oct., 2004

Built website, sent out CFP, corresponded with presenters, designed conference brochure and program, built database for submissions, collected and organized submissions, corresponded with participants and with contractors providing services for conference, make sure all runs smoothly during conference.

Conference Coordinator for the Thomas R. Watson Conference on Rhetoric and Composition,

University of Louisville, Louisville, $K Y$

Registered conference attendees, assisted with questions and problems during conference.

\section{Teaching Experience}

August, 2003May, 2007

August, 2002July, 2003

January, 1998August, 2002

August, 1994October, 1995 (quarter system)

August, 1992May, 1994
University of Louisville, Louisville, $K Y$

Graduate Teaching Assistant

American Literature 1865-1910: Women on the Color Line (Engl 320)

Honors Business Writing (Engl 306) CAI lab

Business Writing (Engl 306) CAI lab

Scientific and Technical Writing (Engl 303) CAI lab

Intermediate College Writing (Engl 102) CAI lab

Introduction to College Writing (Engl 101)

Western Kentucky University, Bowling Green, $K Y$

Full-time English Instructor

Introduction to College Writing

Intermediate College Writing and Research

Introduction to Literature

Western Kentucky University (Glasgow campus), Glasgow, KY

Part-time English Instructor

Introduction to College Writing

Intermediate College Writing and Research

Introduction to Literature

Faulkner University (Mobile campus), Mobile, $A L$

English Instructor

Developmental Writing

Introduction to College Writing

Intermediate College Writing

American Literature I and II

Murray State University, Murray, $K Y$

Graduate Teaching Assistant

Developmental Writing

Introduction to College Writing 


\section{Workshop Presentations}

"Successfully Incorporating Collaboration into the Writing Classroom." Presented with the fellow Assistant Directors of Composition during Instructor Orientation, $U$ of Louisville, August, 2004.

"Literacy for the $21^{\text {st }}$ Century: A Glimpse of the Future through Multimodal Texts." Presented with Dr. Cynthia Selfe and fellow graduate students in the Literacy, Technology, and Education course, U of Louisville, April, 2004.

\section{Honors and Awards}

2005

2004

1990-1992

1989-1992

1988
Dr. M. Celeste Nichols Professional Development Award Faculty Guest Coach, Women's Basketball, University of Louisville (selected by a student scholar-athlete as the instructor who had the greatest influence on her success in the classroom)

\section{Delta Epsilon Sigma, National Scholastic Honor Society}

Bellarmine College Honor Society

Kentucky Governor's Scholar

\section{Professional Memberships}

National Council of Teachers of English, Member

Association of Teachers of Technical Writing, Member

\section{Service}

Brown School Senior Research \& Culminating Projects Boards, Mentor/Advisor, 2007

English Graduate Organization, Graduate Student Representative to the Faculty, 2006-2007

English Graduate Organization, Mentoring Committee, 2005-2006

English Graduate Organization, Executive Board, 2004-2005

English Graduate Organization, Book Sale Committee Co-chair, 2004-2005

English Graduate Organization, Spring Speaker Committee, 2003-2004

\section{Graduate Coursework}

Teaching College Composition (B. Huot, U of Louisville)

Applied Research Methods in Rhetoric and Composition (J. Wolfe, U of Louisville)

History of Rhetoric I (M. Rosner, U of Louisville)

History of Rhetoric II (C. Mattingly, U of Louisville)

Narrative Theory (D. Journet, U of Louisville)

Literacy, Technology, and Education (C. Selfe, U of Louisville)

Genre Theory and Practice (S. Griffin, U of Louisville)

Teaching Professional Writing (G. Cross, U of Louisville)

Passing in the $19^{\text {th }}$ Century (S. Griffin, U of Louisville)

Human Computer Interaction (J. Wolfe, U of Louisville) 
Contemporary Theory \& Interpretation (T. Vann, U of Louisville)

Shakespeare (J. Dietrich, U of Louisville)

\section{References}

Professor Joanna Wolfe, joanna.wolfe a louisville.edu (502) 852-0510

Department of English, University of Louisville, Louisville, KY 40292

Professor Bronwyn T. Williams, btwill02 a louisville.edu (502) 852-6896

Director of Composition, Dept. of English, University of Louisville, Louisville, KY 40292

Professor Debra Journet, dsjourol a louisville.edu (502) 852-3056

Department of English, University of Louisville, Louisville, KY 40292

Humanities Distinguished Professor Cynthia L. Selfe, selfe.2 a osu.edu (614) 688-3779

Department of English, The Ohio State University, Columbus, OH 43210 